\title{
Somatostatin receptor subtype 5 modifies hypothalamic-pituitary-adrenal axis stress function
}

\author{
Masaaki Yamamoto, ${ }^{1}$ Anat Ben-Shlomo, ${ }^{1}$ Hiraku Kameda, ${ }^{1}$ Hidenori Fukuoka, ${ }^{1}$ Nan Deng, ${ }^{2}$ \\ Yan Ding, ${ }^{1}$ and Shlomo Melmed' \\ 1Pituitary Center, Department of Medicine, and 'Biostatistics and Bioinformatics Research Center, Samuel Oschin \\ Comprehensive Cancer Institute, Cedars-Sinai Medical Center, Los Angeles, California, USA.
}

\begin{abstract}
Pituitary corticotroph somatostatin receptor subtype 5 (SSTR5) signals to inhibit adrenocorticotrophin (ACTH) secretion. As ACTH deficiency results in attenuated adrenal cortisol production and an impaired stress response, we sought to clarify the role of SSTR5 in modifying the hypothalamic/pituitary/adrenal (HPA) axis. We generated Tg HP5 mice overexpressing SSTR5 in pituitary corticotrophs that produce the ACTH precursor proopiomelanocortin (POMC). Basal ACTH and corticosterone were similar in HP5 and WT mice, while HP5 mice showed attenuated ACTH and corticosterone responses to corticotrophin releasing hormone (CRH). HP5 mice exhibited attenuated corticosterone responses upon a restraint stress test and inflammatory stress following LPS injection, as well as increased anxiety-like and depressive-like behavior on open field and forced swim tests. Pituitary corticotroph CRH receptor subtype 1 (CRHR1) mRNA expression and ACTH responses to CRH were also attenuated in HP5 mice. In AtT20 cells stably overexpressing SSTR5, CRHR1 expression and cAMP response to CRH were reduced, whereas both were increased after SSTR5 KO. In elucidating mechanisms for these observations, we show that SSTR5-induced miR-449c suppresses both CRHR1 expression and function. We conclude that corticotroph SSTR5 attenuates HPA axis responses via CRHR1 downregulation, suggesting a role for SSTR5 in the pathogenesis of secondary adrenal insufficiency.
\end{abstract}

Authorship note: MY and ABS contributed equally to this work.

Conflict of interest: The authors have declared that no conflict of interest exists.

License: Copyright 2018, American Society for Clinical Investigation.

Submitted: June 18, 2018 Accepted: August 29, 2018 Published: October 4, 2018

Reference information: JCI Insight. 2018;3(19):e122932. https://doi.org/10.1172/jci. insight.122932.

\section{Introduction}

The hypothalamic/pituitary/adrenal (HPA) axis plays a central role in regulating homeostasis, including metabolism, energy storage and expenditure, immunity, and brain functions (1). The HPA axis also enables appropriate stress response. Corticotrophin releasing hormone (CRH) secreted by hypothalamic neurons induces pituitary corticotroph production of the proopiomelanocortin (POMC) precursor polypeptide and enables POMC cleavage by prohormone convertase $1 / 3(\mathrm{PC} 1 / 3)$ to produce adrenocorticotrophin (ACTH). Circulating ACTH, in turn, stimulates adrenal zona fasciculata cells to produce cortisol in humans or corticosterone in rodents (1-4). Low circulating levels of cortisol and/or corticosterone, which characterize hypocortisolism, are observed in ACTH-dependent adrenal insufficiency (AI).

Primary AI results from adrenal-related damage, while secondary AI, resulting from pituitary ACTH deficiency, is typically caused by a hypothalamo-hypophyseal lesion or from a central congenital abnormality. Idiopathic secondary AI and tertiary AI resulting from hypothalamic CRH deficiency are rare (5-7). Clinical features of AI include extreme physical and mental fatigue, depression and anxiety, irritability, lack of appetite and weight loss, body pain, nausea and vomiting, diarrhea, fever, hypotension, and hyponatremia $(8,9)$. If left untreated, especially during stress, AI progresses to adrenal crisis with cardiovascular collapse, often resulting in death (10).

Few animal models are available for the study of secondary AI (11). KO of pituitary developmental transcription factors LHX3 and LHX4, as well as corticotroph transcription factor TPIT, result in corticotroph cell lineage hypoplasia with disrupted ACTH production; these mice have severe baseline hypocortisolism and develop secondary AI (11-13). In KO mice lacking CRH $(14,15)$ or CRH receptor subtype 1 (CRHR1) (16), ACTH levels at baseline are normal but are attenuated in response to stress. Baseline corticosterone levels are also reduced (14-16). 
Somatostatin plays a key role in physiological regulation of the HPA axis $(17,18)$. Hypothalamic somatostatin inhibits pituitary ACTH secretion $(19,20)$, mediated mainly by corticotroph somatostatin receptors subtype 2 (SSTR2) and subtype 5 (SSTR5) (21-23). SSTRs, G-protein coupled receptors (GPCRs), inhibit adenylate cyclase, reduce intracellular cAMP levels, close calcium channels to reduce intracellular calcium levels, and acutely inhibit exocytosis (24-26). Pasireotide, a somatostatin receptor ligand with a preferential high affinity for SSTR5, suppresses ACTH and cortisol levels in some patients with Cushing disease caused by ACTH-secreting pituitary adenomas $(27,28)$.

Consistent with the inhibitory effect of SSTR5 on ACTH secretion, we showed that constitutive human SSTR5 (hSSTR5) activity also inhibits CRH-induced ACTH (29). This action was associated with reduced CRHR1 mRNA expression in mouse AtT20 corticotroph cells overexpressing hSSTR5 (29-31). By contrast, mice devoid of SSTR5 showed increased basal ACTH and corticosterone levels (32). We therefore hypothesized that increased mouse pituitary corticotroph SSTR5 would decrease pituitary ACTH production due to CRHR1 downregulation, resulting in secondary AI and functional decompensation.

We examined the role of corticotroph SSTR5 in adaptive HPA axis responses to stress and elucidated mechanisms underlying SSTR5 modification of adrenal function. Our results show that corticotroph SSTR5 posttranscriptionally suppresses CRHR1 expression and function via induced microRNA, resulting in attenuated corticotroph responses to hypothalamic $\mathrm{CRH}$.

\section{Results}

Generation of human pituitary SSTR5 Tg mice (HP5). Human and mouse SSTR5 share $81 \%$ homology $(33,34)$, and both signal to reduce intracellular calcium and cAMP levels (35). Accordingly, we generated corticotroph-targeted Tg mice expressing pituitary hSSTR5, termed HP5, using a corticotroph-specific artificial promoter (36) driving N-terminally HA-linked hSSTR5 (Figure 1A). The promoter was originally derived from Tg mice employing the rat Pomc ( $r P o m c)$ promoter $(37,38)$. To enhance corticotroph hSSTR5 specificity and expression levels (39), multiple copies of NeuroD1 and Tpit/Pitx binding sequences were inserted upstream of the $r P o m c$ promoter. Both Western blotting and quantitative PCR (qPCR) showed HA-hSSTR5 expression in the pituitary but not in hypothalamic or adrenal tissue (Figure 1B, Supplemental Figure 1A; supplemental material available online with this article; https://doi.org/10.1172/jci.insight.122932DS1). Female and male HP5 mice demonstrated similar patterns of hSSTR5 expression (data not shown). As female nulliparous mice have higher corticosterone levels than males $(40,41)$, subsequent experiments were performed with female HP5 mice aged 6-12 months.

To examine pituitary gland distribution of hSSTR5, we dissected the anterior lobe (AL) from the intermediate lobe (IL) and posterior lobe (PL), confirmed by Western blot using pituitary-specific markers (42). As expected, PC1/3 was present in both AL and IL+PL, while PC2 and AVP were expressed in IL+PL; POMC was more abundant in IL+PL (Supplemental Figure 1B). Avp mRNA was restricted to IL+PL, as assessed by qPCR (Supplemental Figure 1C). hSSTR5 was more abundant in IL+PL compared with AL (Supplemental Figure 1, D and E), but it was clearly expressed in AL when separately compared against WT (Supplemental Figure 1F). We observed POMC immunofluorescence in AL and IL in both WT and HP5 pituitary (Figure 1, C and D). hSSTR5 was more abundant in IL compared with AL in HP5 and was not expressed in WT (Figure 1, C and D). Colocalization of hSSTR5 and POMC in HP5 AL was confirmed by confocal immunofluorescence microscopy (Figure 1E), demonstrating corticotroph hSSTR5 expression.

HP5 mice maintain baseline pituitary-adrenal function. In HP5 and WT mice, body weight and food consumption were similar up to 23 months of age (Supplemental Figure 2, A and B). At baseline, morning circulating $\mathrm{ACTH}, \alpha \mathrm{MSH}$, and corticosterone levels were similar in HP5 and WT mice (Figure 2, A-C), as were levels of prolactin, insulin-like growth factor-I (IGF-I), fasting serum glucose, and insulin (Supplemental Figure 2, C-F). HP5 adrenal gland size (Figure 2D) and weight ( $P=0.004$; Figure 2E) were lower than those encountered in WT mice. Accordingly, on H\&E staining, adrenal cortex width was narrower in HP5 than in WT mice ( $0.45 \pm 0.02$ vs. $0.29 \pm 0.03 \mathrm{~mm}$, respectively; $P=0.0009)$ (Figure $2, \mathrm{~F}-\mathrm{H})$.

Attenuated HPA axis response to stress in HP5 mice. To assess HPA axis function in HP5 mice, we measured ACTH and corticosterone before and 30 minutes after a single injection of $40 \mu \mathrm{g} / \mathrm{kg} \mathrm{CRH}$. Although baseline ACTH and corticosterone levels were similar in WT and HP5 mice (Figure 2, A and $\mathrm{C}$ ), evoked ACTH and corticosterone responses to $\mathrm{CRH}$ were attenuated in HP5 mice (ACTH, 
A

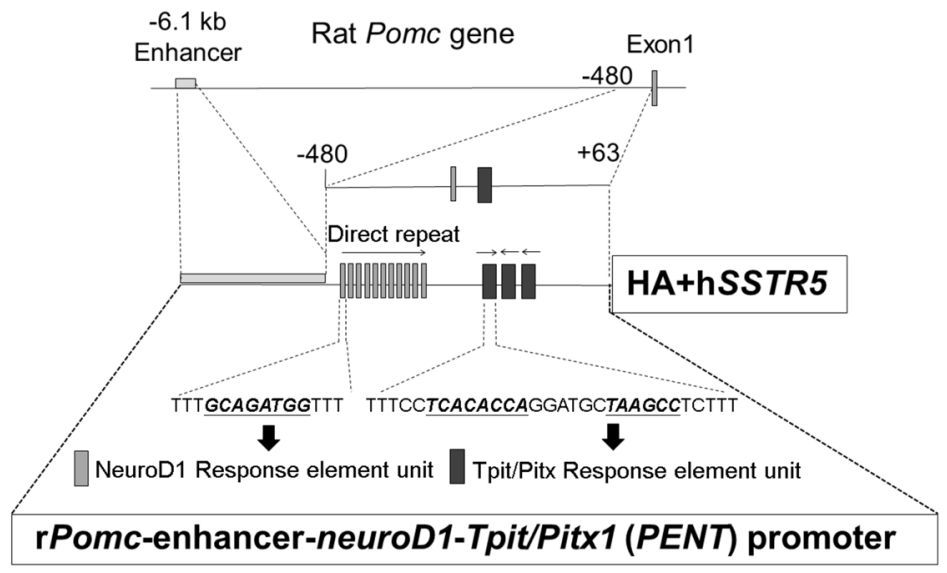

B

B $\quad \frac{\text { Hypothalamus }}{\text { WT HP5 }} \frac{\text { Pituitary }}{\text { WT HP5 }} \frac{\text { Adrenal }}{\text { WT HP5 }}$

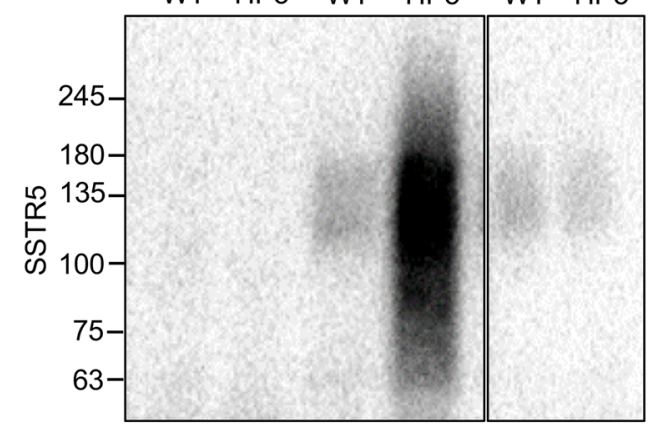

C

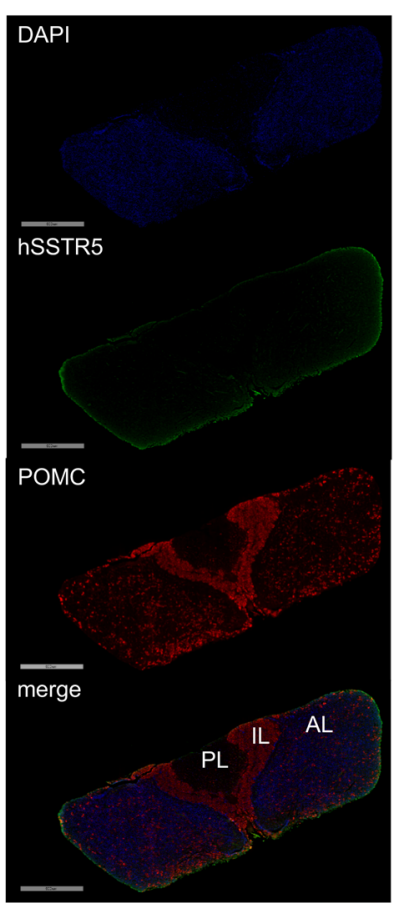

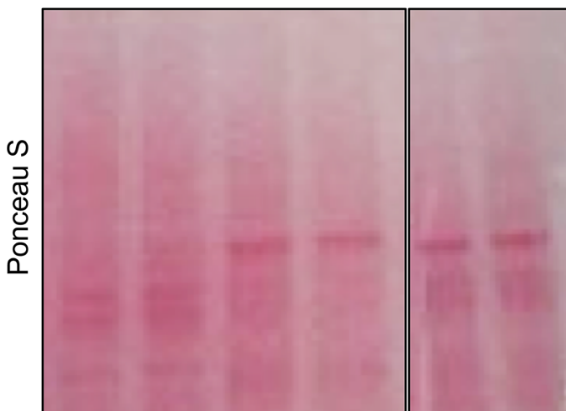

D

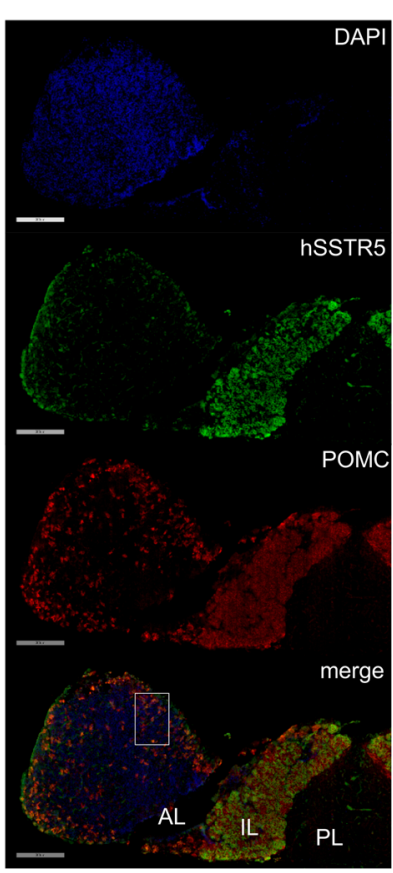

E

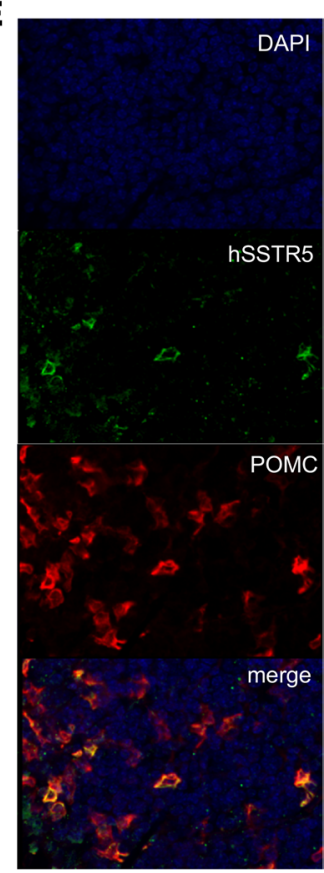

Figure 1. Morphologic characterization of HP5 transgenic mice. (A) Construct map of rat Pomc-enhancer-neuroD1-Tpit/Pitx1 (PENT) promoter with HA-tagged human SSTR5 gene (33). (B) Western blot analysis of HA-hSSTR5 expression in wholecell extracts derived from the hypothalamus, pituitary, and adrenal glands of WT and HP5 mice. Anti-HA antibody was used to detect hSSTR5, and Ponceau S staining served as the loading control. (C-E) Immunofluorescent staining of (C) WT and (D) HP5 pituitary; rectangle in $\mathbf{D}$ is enlarged and shown in $\mathbf{E}$ using anti-DAPI, anti-hSSTR5, and anti-POMC; merged image is also depicted. Staining was analyzed by confocal microscopy. Scale bars: $500 \mu \mathrm{m}$ in C and $200 \mu \mathrm{m}$ in $\mathbf{D}$. $\mathrm{AL}$, anterior lobe; IL, intermediate lobe; $\mathrm{PL}$, posterior lobe.

$P=0.06$; Figure 3A; corticosterone, $P<0.0001$; Figure 3B). Next, we treated mice with the somatostatin receptor ligand pasireotide long-acting release (LAR) in expectation of enhancing hSSTR5 signaling, given its high affinity for SSTR5. After 35 days of pasireotide LAR treatment (Supplemental Figure 3A), IGF-I levels were reduced in both WT $(P=0.01)$ and HP5 mice $(P<0.0001)$ (Supplemental Figure 3D), while unstimulated ACTH and corticosterone levels were not altered (Supplemental Figure 3, B and C). However, pasireotide-treated HP5 mice exhibited a blunted response to $\mathrm{CRH}$, exhibiting 
A

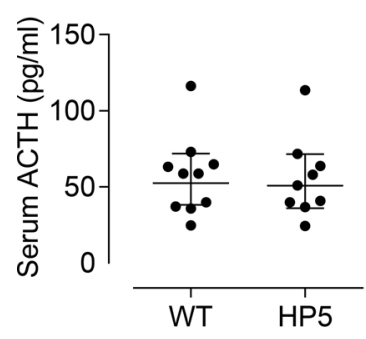

B

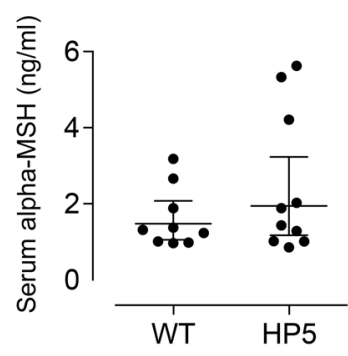

C

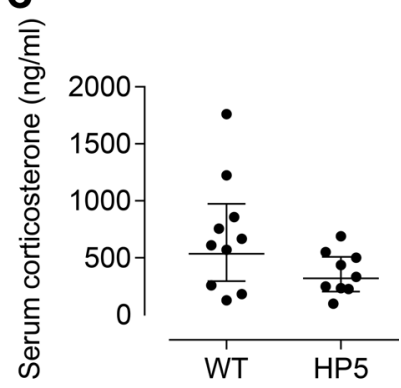

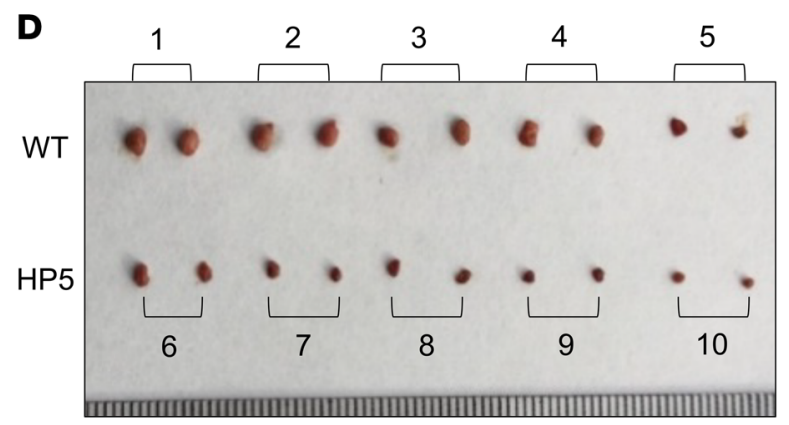

E

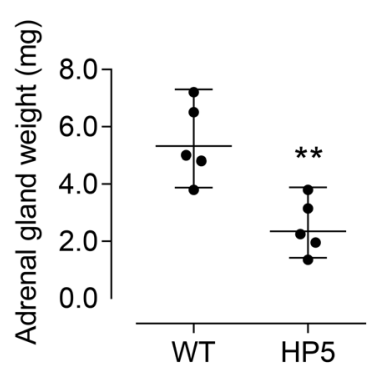

$\mathbf{F}$

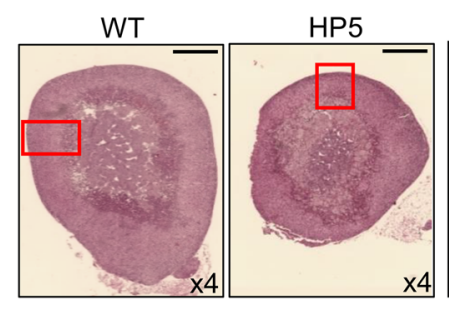

G

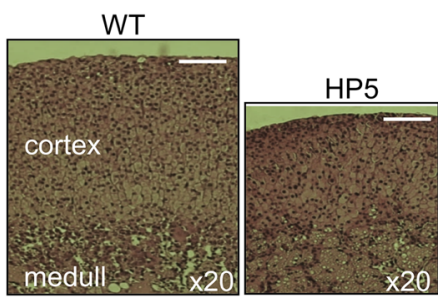

H

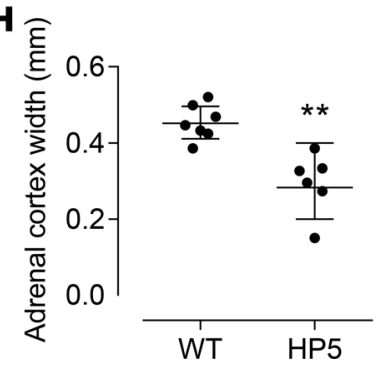

Figure 2. HP5 mice maintain baseline pituitary-adrenal function. (A) Baseline ACTH in WT $(n=10)$ and HP5 $(n=9)$ mice. (B) Baseline $\alpha$ MSH in WT $(n=9)$ and HP5 $(n=10)$ mice. (C) Baseline corticosterone levels in WT $(n=10)$ and HP5 $(n=9)$ mice. Pathology of adrenal glands collected from WT and HP5 mice. (D) Whole WT (upper) and HP5 (lower) adrenal glands. (E) Weight of WT $(n=5)$ and HP5 $(n=5)$ adrenal glands $\left({ }^{*} P=0.004\right)$. (F and $\left.\mathbf{G}\right)$ Microscopic images of WT (left) and HP5 (right) adrenal glands stained by H\&E. (F) Lower magnification ( $\times 4)$. Scale bars: $500 \mu \mathrm{m}$. (G) Higher magnification $(\times 20)$. Scale bars: $100 \mu \mathrm{m}$. (H) Width of WT $(n=7)$ and HP5 $(n=6)$ adrenal cortex. Results are presented as mean \pm SEM. ${ }^{* *} P \leq 0.005$, 2-tailed, unpaired $t$ test.

lower ACTH $(P=0.004)$ and lower corticosterone $(P=0.001)$ after CRH stimulation compared with pasireotide-treated WT mice (Supplemental Figure 3, E and F).

To evaluate changes in corticotroph SSTR5 signaling under stress conditions, mice were restrained for 30 minutes (physiological stress) or treated with LPS (inflammatory stress). The corticosterone response was attenuated in HP5 vs. WT mice after 30 minutes of restraint ( $P=0.008$; Figure $3 C)$, as well as 2 hours after $10 \mathrm{mg} / \mathrm{kg}$ LPS injection ( $P=0.03$; Figure 3D). Seventy-two hours after $5 \mathrm{mg} / \mathrm{kg}$ LPS injection, HP5 mice lost significant body weight, while WT body weight was not altered $(P=0.02$; Figure $3 \mathrm{E})$. Importantly, although WT mice were highly mobile and active with unchanged fur, HP5 mice had lost weight and fur, were emaciated, and were less mobile(Supplemental Video 1$)$. We scored mouse body condition and well-being 72 hours after $10 \mathrm{mg} / \mathrm{kg}$ LPS administration ( $n=10$ per group) and found that more HP5 than WT mice exhibited a body condition score of 1 (BCS1), indicating the poorest health condition $(30 \% \mathrm{vs}$. $10 \%$ ), while more well-conditioned mice with BCS3 were observed in the WT (50\%) than in the HP5 group (10\%); 4 HP5 mice and 1 WT mouse died after LPS injection (Figure 3F). These results demonstrate that HP5 mice tolerated extreme inflammatory response less favorably than did WT mice.

Anxiety- and depressive-like phenotype in HP5 mice. We next assessed HP5 and WT mice for behavioral changes including anxiety and depression, known to be associated with HPA axis dysfunction $(43,44)$. During a 60-minute open field test, HP5 mice exhibited less locomotor activity $(P=0.05$; Figure 4A), 
A
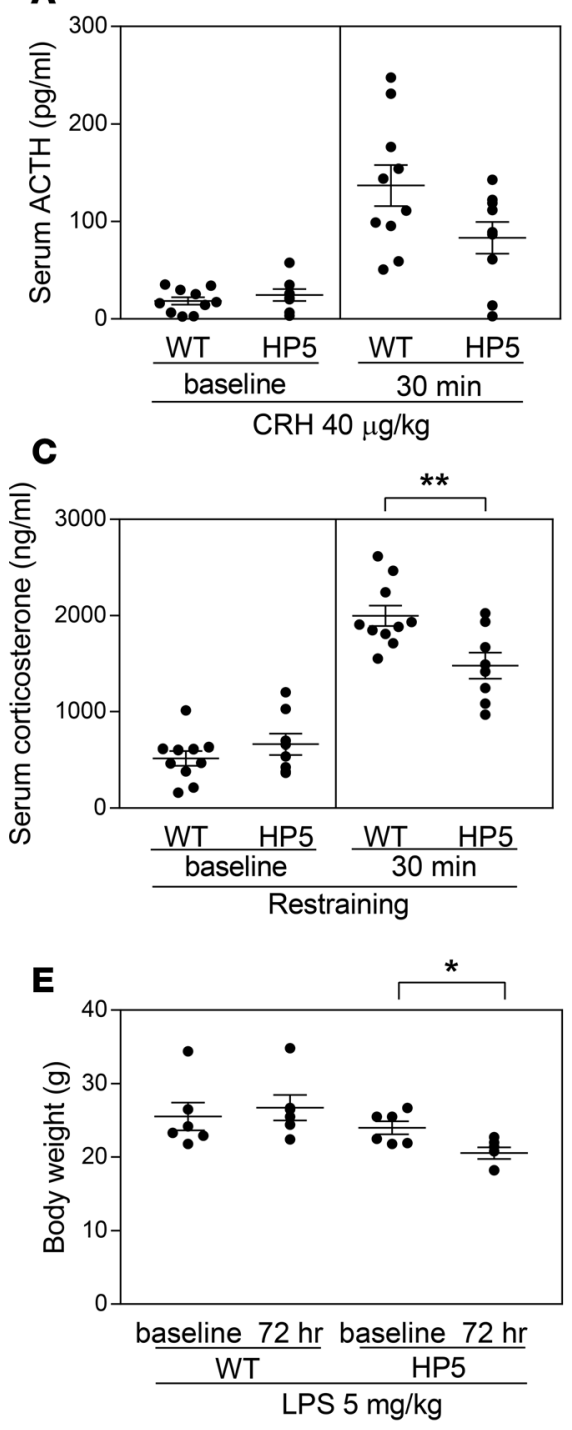

B



$\mathrm{CRH} 40 \mu \mathrm{g} / \mathrm{kg}$

D



LPS $10 \mathrm{mg} / \mathrm{kg}$

$\mathbf{F}$

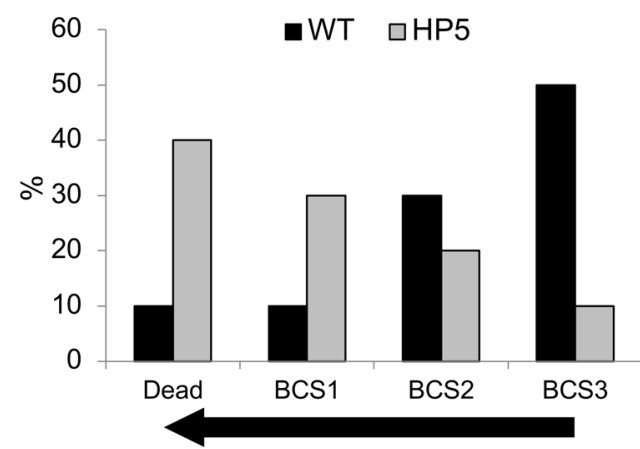

Reduced Health Condition
Figure 3. HP5 exhibit attenuated

ACTH-corticosterone responses to stress. (A and B) Morning ACTH and corticosterone levels measured before (baseline) and 30 minutes after $40 \mathrm{mg} / \mathrm{kg}$ i.p. CRH administration in WT and HP5 mice. (A) ACTH measured in WT $(n=10)$ and HP5 $(n=9)$ mice. (B) Corticosterone measured in WT $(n=9)$ and HP5 $(n=9)$ mice. (C) Morning corticosterone levels before (baseline) and 30 minutes after restraint stress in WT $(n=10)$ and HP5 $(n=8)$ mice. (D) Morning corticosterone levels before (baseline) and 120 minutes after $10 \mathrm{mg} / \mathrm{kg}$ LPS injection in WT $(n=10)$ and HP5 $(n=$ 10) mice. (E) Body weight before (baseline) and 72 hours after $5 \mathrm{mg} / \mathrm{kg}$ LPS injection in WT $(n=6)$ and HP5 $(n=6)$ mice. (F) Death and body condition scores (BCS) 72 hours after $10 \mathrm{mg} / \mathrm{kg}$ LPS injection in WT $(n=10)$ and HP5 $(n=10)$ mice. BCS1, emaciated; BCS2, under-conditioned; BCS3, well-conditioned. All experiments were performed with different mouse groups. Results are presented as mean \pm SEM. ${ }^{*} P$ $\leq 0.05$; ${ }^{*} P \leq 0.01$; ${ }^{* *} P \leq 0.001 ; 2$-tailed, unpaired $t$ test.

longer resting time ( $P=0.02$; Figure $4 \mathrm{~B})$, and less moving distance $(P=0.04$; Figure $4 \mathrm{C})$ compared with WT mice, but no difference in traveling speed was seen (Figure 4D). Less rearing behavior was observed in HP5 mice during the first 10 minutes when exploring the new chamber $(P=0.02$ for $0-5$ min; Figure $4 \mathrm{E})$ but not later. HP5 mice also spent less time $(P=0.04$; Figure $4 \mathrm{~F})$ and were less active $(P=0.05$; Figure $4 \mathrm{G}$ ) in the center of the cage. Together, these behaviors indicate that HP5 are more anxious than WT mice. In performing the 6-minute forced swim test, HP5 mice exhibited decreased total swimming time $(P=0.002 ;$ Figure $4 \mathrm{H})$ and increased immobile time $(P=0.004$; Figure $4 \mathrm{I})$, and they had a greater immobile/total time ratio $(P=0.001$; Figure $4 \mathrm{~J})$ compared with WT mice. Latency time to immobility was also shorter in HP5 mice $(P=0.0008$; Figure $4 \mathrm{~K})$. These results indicate that HP5 mice exhibit a more depressive-like behavior than do WT mice.

Pituitary CRHR1 expression and action are attenuated in HP5 mice. We next examined mechanisms underlying SSTR5-mediated attenuation of the HPA axis. Hypothalamic Crh and Avp mRNA expression levels were not altered in HP5 or WT (Figure 5, A and B). However, HP5 pituitary glands expressed significantly less $\operatorname{Crhr} 1$ mRNA ( $P=0.001$; Figure $5 C)$ and more Avpr $1 b$ mRNA $(P=0.05$, Figure 5D), while Tpit (Figure 5E), Pomc (Figure 5F), and Pitx1 (Figure 5G) mRNA expression levels were similar to those in WT. Growth hormone (Gh1), serving as a control, was unchanged, indicating a cell-specific corticotroph effect (Figure 5H). Western blot analysis confirmed that whole pituitary CRHR1 abundance 

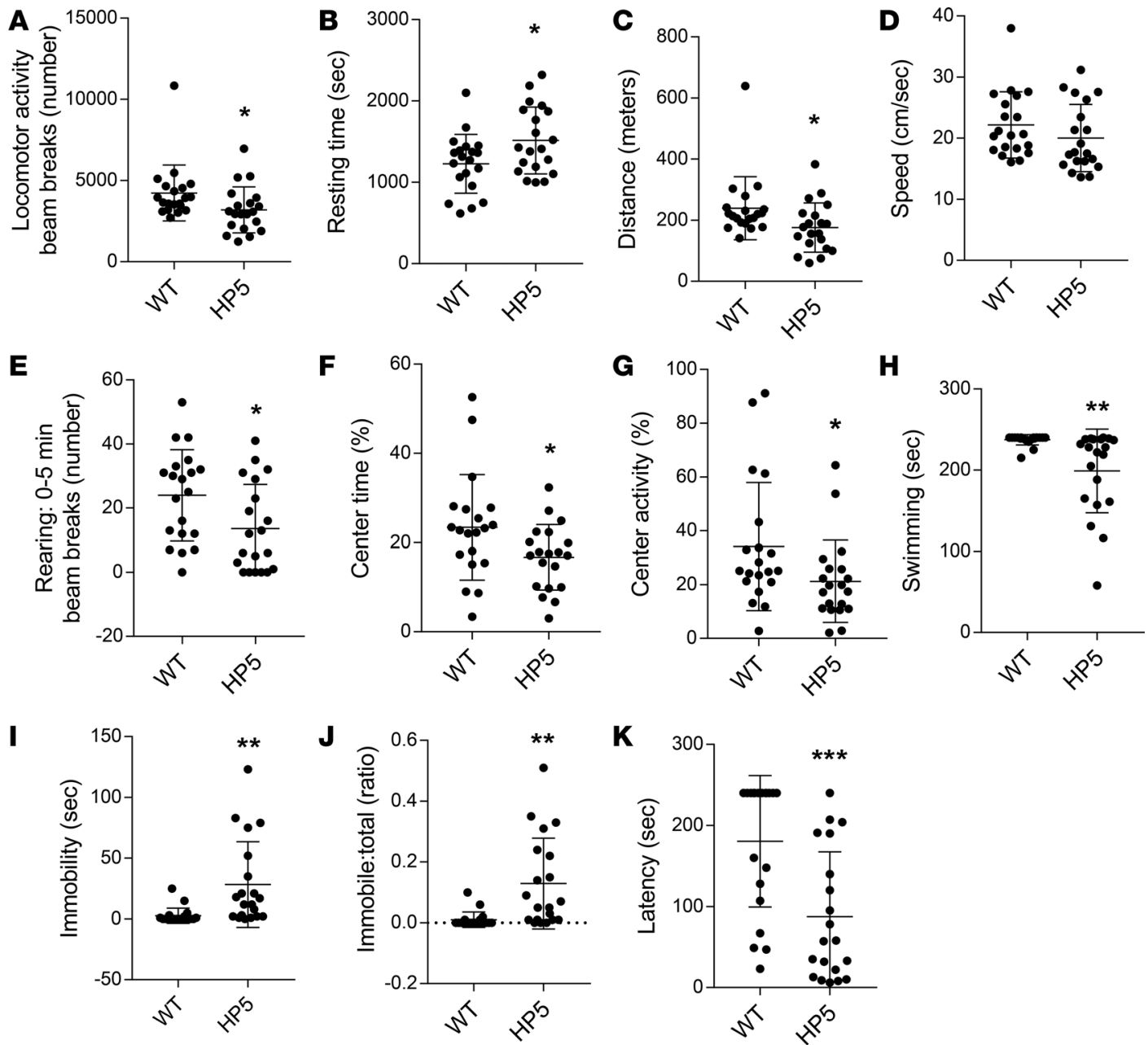

Figure 4. Anxiety- and depressive-like phenotype in HP5 mice. (A-C) Exploratory/anxiety behavior in WT $(n=20)$ and HP5 $(n=20)$ mice assessed by openfield test. Locomotor activity was assessed by $(\mathbf{A})$ number of horizontal beam breaks using the lower ring of photobeams in the entire chamber; (B) resting time (seconds); (C) distance moved (meters); (D) speed (centimeters/second); (E) rearing, defined as the number of vertical beam breaks using the upper ring of photobeams during each 5-minute time block from 0-10 minutes; (F) center time, defined as the percentage of time spent in the center area; and (G) center activity, defined as the percentage of horizontal beam breaks occurring in the center area. (H-K) Depression-like behavior in WT ( $n=20)$ and HP5 ( $n=20)$ mice assessed by 6-minute forced swim test assessed by (H) duration of swimming (seconds); (I) duration of immobility (seconds); (J) ratio of immobility to total time; and (K) latency time to immobility (seconds). Results are presented as mean \pm SEM. ${ }^{*} P \leq 0.05 ;{ }^{* *} P \leq 0.01 ;{ }^{* *} P \leq 0.001 ; 2$-tailed, unpaired $t$ test.

in HP5 was reduced compared with WT ( $P=0.02$; Figure 5 , I and J), and no difference in TPIT, POMC, and GH expression abundance were noted (Figure 5, I and K-M). Pituitary AL was dissected from IL and PL and analyzed separately by Western blot. AL POMC $(P=0.004$; Supplemental Figure 4, A and B) and CRHR1 ( $P=0.01$; Supplemental Figure 4, A and C) expression were decreased as compared with WT, but AL TPIT and GH expression were similar (Supplemental Figure 4, A, D, and E). In line with these observations, in whole pituitary-derived cell cultures, CRH dose-dependent induction of ACTH response was attenuated in HP5 cells (Figure 5N). In contrast, AVP dose-dependent induction of ACTH response was enhanced (Figure 5O) as compared with WT, suggesting that HP5 mice compensate for reduced CRHR1 levels by increasing the AVP response.

SSTR 5 suppresses corticotroph CRHR 1 expression and signaling. To determine whether SSTR5 alters CRHR1 expression, we treated primary pituitary cells derived from SSTR2-KO mice with pasireotide, which has a high affinity for SSTR5, and employed octreotide, which has a high affinity for SSTR2, as a negative control. Pasireotide but not octreotide suppressed Crhr1 mRNA levels $(P=0.03$; Figure 6A), while levels of Pitx1, Tpit, NeuroD1, and Pomc mRNA levels were similar (Figure 6A). Furthermore, Crhr1 mRNA ( $P=$ $0.0007)$ and CRHR1 protein $(P=0.003)$ levels were markedly suppressed in AtT20 mouse corticotroph cells stably expressing hSSTR5 compared with control (Figure 6, B-D). To confirm the requirement of SSTR5 
A
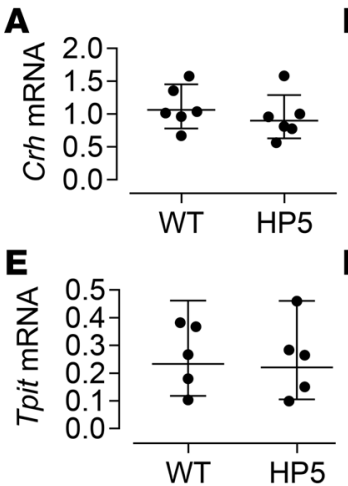

B

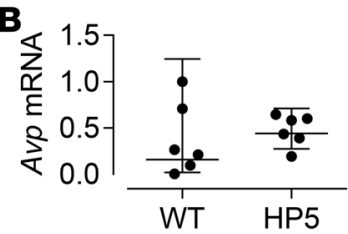

$F$

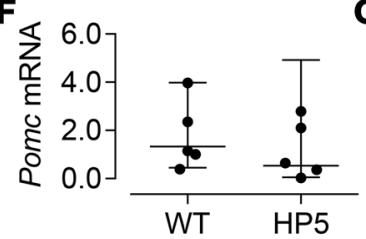

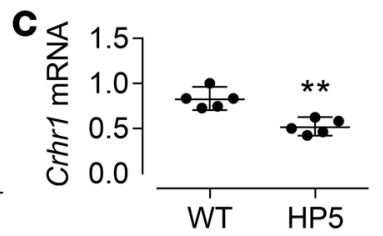

G

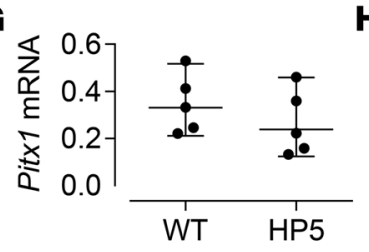

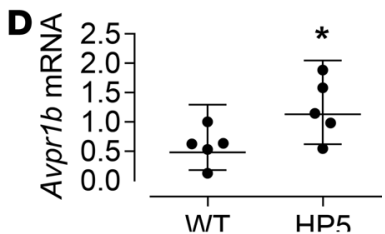

H

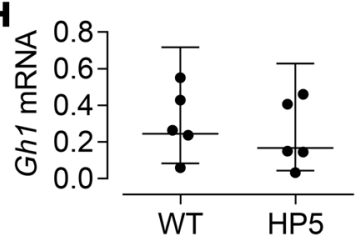

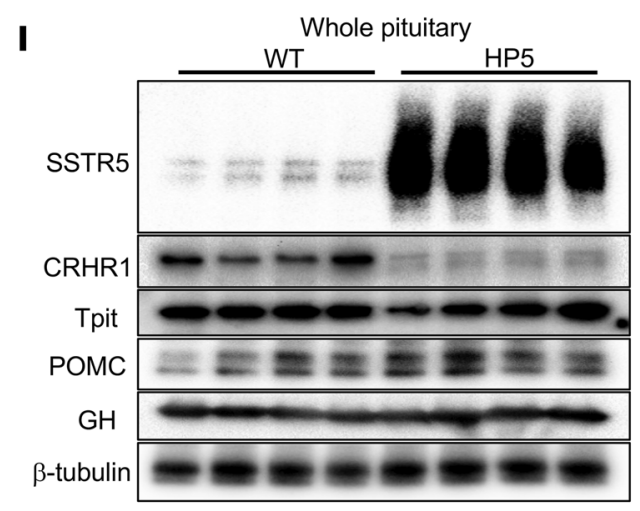

$\mathbf{N}$

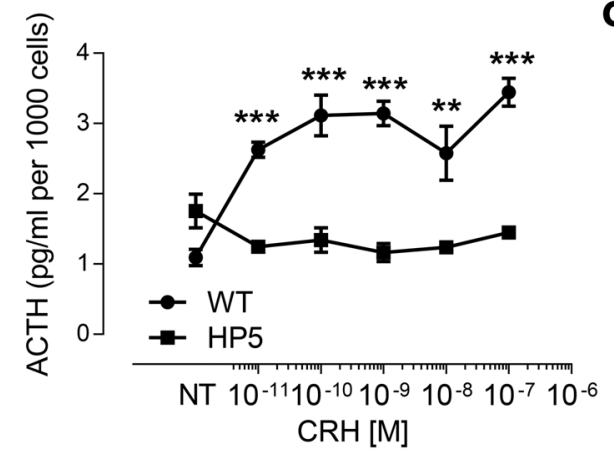

$\mathbf{J}$
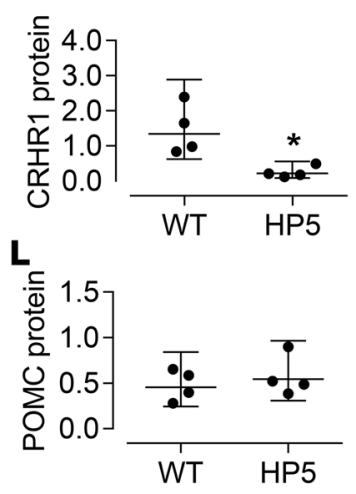

K
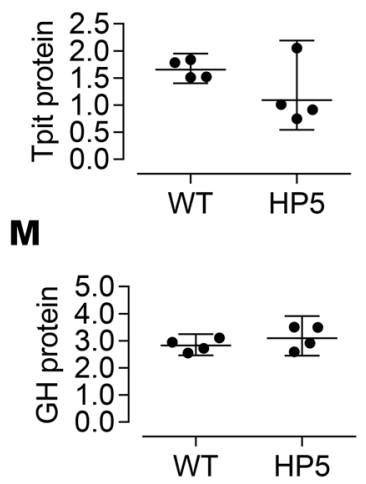

0



Figure 5. Pituitary CRHR1 expression and action are attenuated in HP5 mice. Hypothalamic expression of (A) Crh and (B) Avp mRNA levels derived from WT $(n=6)$ and HP5 $(n=6)$ mice. Relative mRNA levels of (C) Crhr1, (D) Avpr1b, (E) Tpit, (F) Pomc, (C) Pitx1, and (H) Gh1 in pituitary tissue from WT ( $n=$ 5) and HP5 $(n=5)$ mice as determined by qPCR and normalized to Gapdh. (I) Western blot analysis of 4 WT and 4 HP5 whole pituitaries for CRHR1, Tpit, POMC, and GH protein and compared with $\beta$-tubulin. (J-M) Quantitative analysis of Western blot results in I performed by scanning densitometry. Protein levels were normalized to $\beta$-tubulin. (N) CRH-stimulated ACTH levels measured by ELISA in the culture medium of whole pituitary glands ( $8.0 \times 10^{4}$ cells/ well, $n=4$ at each CRH concentration) collected from WT $(n=5)$ and HP5 $(n=5)$ mice. ACTH level $(\mathrm{pg} / \mathrm{ml})$ was normalized to cell number (per 1,000 cells). (0) AVP-stimulated ACTH levels measured by ELISA in the culture medium of whole pituitary glands $\left(2.0 \times 10^{5}\right.$ cells/well, $n=4$ at each CRH concentration) collected from WT $(n=10)$ and HP5 $(n=10)$ mice. ACTH level $(\mathrm{pg} / \mathrm{ml})$ was normalized to WST-1 absorbance. Results are presented as mean \pm SEM. Experiments were repeated in triplicate $(\mathbf{N})$ or duplicate $(\mathbf{O})$, and cells were plated in quadruplicate wells. Representative results are presented. ${ }^{*} P \leq 0.05 ;{ }^{* *} P \leq$ $0.01,{ }^{* *} P \leq 0.001$; 2-tailed unpaired $t$ test, ( $\mathbf{N}$ and $\mathbf{O}$ ) with Bonferroni correction.

for CRHR1 suppression, we depleted CRHR1 transfectants by generating 3 independent clones (KO\#1, KO\#2, and KO\#3) of SSTR5-KO AtT20 cells using CRISPR/Cas9 (Supplemental Figure 5A). Three outof-frame mutations were confirmed by Sanger sequencing (Supplemental Figure 5, B and C) and predicted defective SSTR5 transmembrane domains by transmembrane helix prediction program (TMHMM; http:// www.cbs.dtu.dk/services/TMHMM/) (Supplemental Figure 5D). Unlike WT cells, which were responsive to the selective SSTR5 agonist BIM-23206, SSTR5-KO clones lost responsiveness to BIM-23206, which did not inhibit intracellular cAMP accumulation (Supplemental Figure 5E). These results confirm functional elimination of SSTR5-related cAMP signaling in these cells. Crhr1 mRNA $(P=0.0002$, Figure 6E) and 

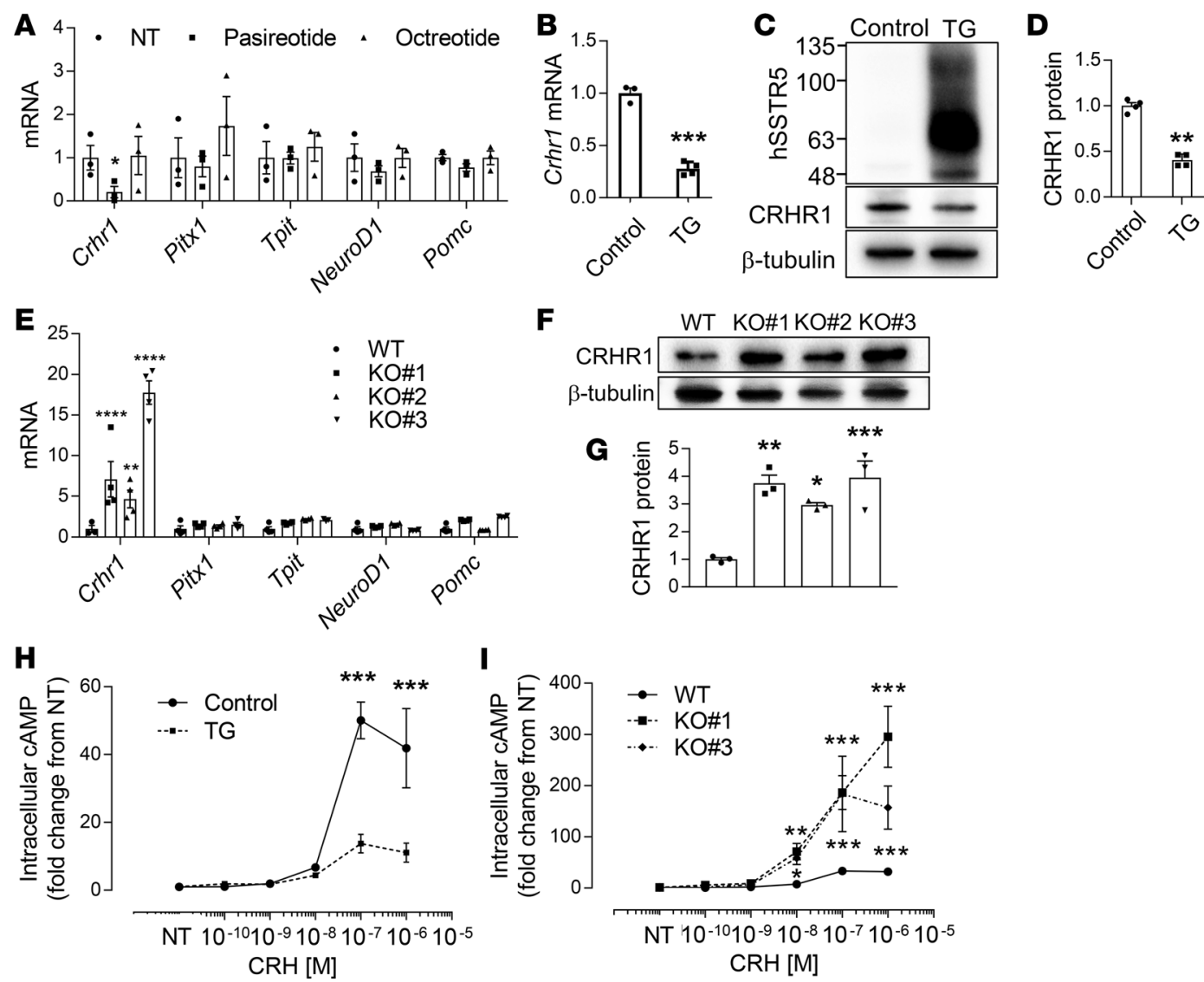

Figure 6. SSTR5 suppresses corticotroph CRHR1 expression and signaling. (A) mRNA expression levels determined by qPCR in primary pituitary cell culture $\left(2 \times 10^{5}\right.$ cells/well; $\left.n=3\right)$ derived from SSTR2-KO mice administered no treatment (NT), pasireotide $1 \mathrm{nM}$, or octreotide $1 \mathrm{nM}$ for 24 hours. (B-D) mRNA and protein expression in transgenic (Tg) AtT20/D16v-F2 cells stably expressing hSSTR5-IRES-ZsGreen and AtT20/D16v-F2 cells expressing only pZsGreen1-N1 (B) Crhr1 mRNA expression levels measured by qPCR ( $n=3 /$ group). (C) Western blot analysis of hSSTR5 and CRHR1 compared with $\beta$-tubulin. (D) Quantification analysis of CRHR1 normalized to $\beta$-tubulin. (E) mRNA levels of the indicated genes as expressed in SSTR5-KO AtT20 cell clones (KO\#1-3) compared with cells that maintain intact SSTR5 (WT). (F) Western blot analysis of CRHR1 in WT and KO\#1-3 cells compared with $\beta$-tubulin as loading control, and (G) quantification of CRHR1 normalized to $\beta$-tubulin in WT compared with K0\#1-3 ( $n=3 /$ group). (H and I) Intracellular cAMP levels after treatment with increasing doses of CRH for 30 minutes in (H) hSSTR5-expressing AtT20 clones (Tg) and (I) KO\#1 and KO\#3 AtT20 clones compared with respective controls. $Y$ axis represents fold change in CAMP from CRH-untreated cells (NT) measured with the LANCE cAMP assay. Samples contained $8.0 \times$ $10^{4}$ cells/well; $n=4$ for each CRH concentration. Results are presented as mean \pm SEM. Experiments were repeated in triplicate, and representative results are shown ( $\mathbf{H}$ and $\mathbf{I}$ ). ${ }^{*} P \leq 0.05 ;{ }^{* *} P \leq 0.01 ;{ }^{* *} P \leq 0.001 ;{ }^{* * * *} P \leq 0.0001 ; 2$-tailed unpaired $t$ test, $(\mathbf{H}$ and $\mathbf{I}$ ) with Bonferroni correction.

CRHR1 protein $(P=0.001$; Figure $6, \mathrm{~F}$ and $\mathrm{G})$ levels were higher in all SSTR5-KO clones compared with WT controls, suggesting that constitutive SSTR5 activity suppresses CRHR1 expression. By contrast, Pitx1, Tpit, NeuroD1, and Pomc mRNA levels were similar to controls (Figure 6E).

To test whether SSTR5 negatively regulates CRHR1 downstream signaling, we measured CRH-dependent intracellular cAMP production. Cells overexpressing hSSTR5 exhibited blunted CRH-induced cAMP accumulation compared with controls (Figure 6H), while SSTR5-KO cells showed enhanced cAMP responses to CRH compared with WT controls (Figure 6I). We therefore conclude that SSTR5 suppresses CRH-dependent CAMP production via downregulation of CRHR1. In turn, ACTH production is suppressed, resulting in lower corticosterone production.

SSTR 5 downregulates CRHR1 signaling via miRNA-449c. To address mechanisms for SSTR 5 suppression of Crhr1 mRNA expression, we first investigated transcriptional regulation of Crhr1 by SSTR5. Based on data available for human CRHR1 (45), we studied a region $-2.4 \mathrm{~kb}$ upstream of the end of the $3^{\prime} \mathrm{UTR}$. Fourteen regions were highly conserved between human and mouse (Supplemental Figure 6A), and noncoding sequences of the Crhrl locus were selected. ChIP analysis measuring histone acetylation level in these regions showed that a region located in the proximal $5^{\prime} \mathrm{UTR}$ was highly acetylated compared with the other regions (Supplemental Figure 6B). Crhrl promoter activity was therefore analyzed in and adjacent to 
this region. We generated constructs to measure mouse Crhrl promoter activity by luciferase assay (Supplemental Figure 6C) and transfected them into SSTR5-overexpressing AtT20 cells (Tg, Supplemental Figure 6D) or from SSTR5-KO AtT20 cells (KO\#1-3, Supplemental Figure 6E). Compared with their respective controls, SSTR5 expression status did not alter Crhr1 promoter activity (Supplemental Figure 6, D and E).

Based on our results, we hypothesized that SSTR5 did not affect Crhr1 transcription but rather reduced mRNA stability, and we therefore explored whether microRNA changes could account for these effects. To test this hypothesis, we identified 25 candidate miRNAs that likely bind mouse Crhr1 3'UTR based on the microRNA database (www.microRNA.org) and chose those with Ct value $<35$ by qPCR in AtT20 cells and mouse pituitary tissue (data not shown). Twelve miRNAs were suppressed in SSTR5-KO cells $\leq 0.5$-fold in at least 1 of 2 clones compared with WT (Figure 7A and Supplemental Figure 7A). Eight miRNAs were induced $\geq 1$.8-fold in hSSTR5-overexpressing transfectants compared with control (Figure 7A and Supplemental Figure 7B), and expression levels of 8 miRNAs were induced $\geq 1.8$ times in HP5 mouse pituitary compared with control (Figure 7A and Supplemental Figure 7C).

We focused subsequent experiments on 7 miRNAs that showed similar changes in HP5 vs. WT pituitaries, as well as in Tg vs. control AtT20 cells, and that showed contrasting changes in KO and WT AtT20 cells (Figure 7A). We generated oligonucleotide inhibitors to the selected miRNAs, transfected AtT20 WT cells with each of these respective inhibitors, and tested Crhrl mRNA expression as compared with scramble transfected cells. Inhibition of miR-449c $(P=0.008)$ and miR-322 $(P=0.03)$, but not the other tested miRNAs, selectively enhanced Crhr1 expression as assessed by qPCR (Figure 7B). Treatment with a pharmacologic miR-449c inhibitor significantly enhanced CRHR1 protein levels in WT AtT20 cells $(P=0.02$; Figure 7C). Similar to reports in other tissues (46), we found that miR-449c also suppresses $M y c$ mRNA in HP5 pituitary $(P=0.006$; Supplemental Figure $8 \mathrm{~A})$ and that AtT20 cells treated with miR-449c inhibitor showed increased c-Myc protein expression ( $P=0.04$; Supplemental Figure $8, \mathrm{~B}$ and $\mathrm{C}$ ). Inhibition of miR-449c in primary HP5 pituitary cell cultures rescued $\mathrm{CRH}$-dependent ACTH secretion to the culture medium (Figure 7D). In addition, when we overexpressed miR-449c in AtT20 cells (Figure 7E), only Crhr 1 but not other pituitary-specific genes were suppressed (Figure 7F). To confirm that miR-449c participates in SSTR5-mediated CRHR1 inhibition, we transfected miR-449c into SSTR5-KO AtT20 cells and observed marked suppression of CRH-induced cAMP accumulation in the absence of SSTR5 (Figure 7G). Taken together, these results demonstrate that miR-449c likely mediates negative pituitary regulation of CRHR1 by SSTR5 signaling.

\section{Discussion}

The HP5 mouse overexpressing pituitary corticotroph SSTR5 recapitulates some clinical and biochemical phenotypes of secondary AI when exposed to behavioral or inflammatory stress. We showed that SSTR5 suppresses CRH action in response to stress by reducing corticotroph cell CRHR1 expression. To our knowledge, this mechanism, whereby a receptor not directly associated with the HPA axis regulates HPA axis function, has not been previously reported

HP5 and CRHR1-KO mice exhibit some similar features. Adrenal cortex is atrophied, and ACTH and corticosterone levels are attenuated, upon stress in both models (16, 47-49). However, low baseline corticosterone levels are observed in CRHR1-KO but not in HP5 mice as compared with controls $(16,48)$. Baseline corticosterone and ACTH level may be preserved in HP5 mice due to increased AVP action, as HP5 pituitaries demonstrated higher levels of Avprlb receptor mRNA and increased response to AVP. Basal AVP levels are also significantly increased in CRHR1-KO mice (48). Thus, our findings suggest that AVP upregulation may compensate for baseline ACTH deficiency. Consistent with normal corticosterone levels in HP5, treatment with pasireotide, a somatostatin receptor ligand with a high affinity for SSTR5, had no further suppressive effect on unstimulated corticosterone levels both in WT and HP5. These results also suggest that SSTR5 may not play a role in basal corticosterone regulation.

Utility of the HP5 mouse is clearly demonstrated when considering the clinical picture of patients with secondary AI. As is seen in CRH-KO and CRHR1-KO mice $(14,16)$, HP5 mice show deconditioning and significantly attenuated ACTH and corticosterone responses to restraint and inflammatory stress. Importantly, however, HP5 mice show normal growth and development in unstressed conditions and only exhibit significant deterioration in health status when exposed to inflammatory stress. This is akin to human subjects with secondary AI, who show baseline cortisol levels within the low-normal range and, only upon stimulation, demonstrate a lack of appropriate cortisol response. Indeed, stimulated cortisol levels are required to validate $\mathrm{AI}$, with baseline cortisol levels serving only as a screening modality (43). 
A

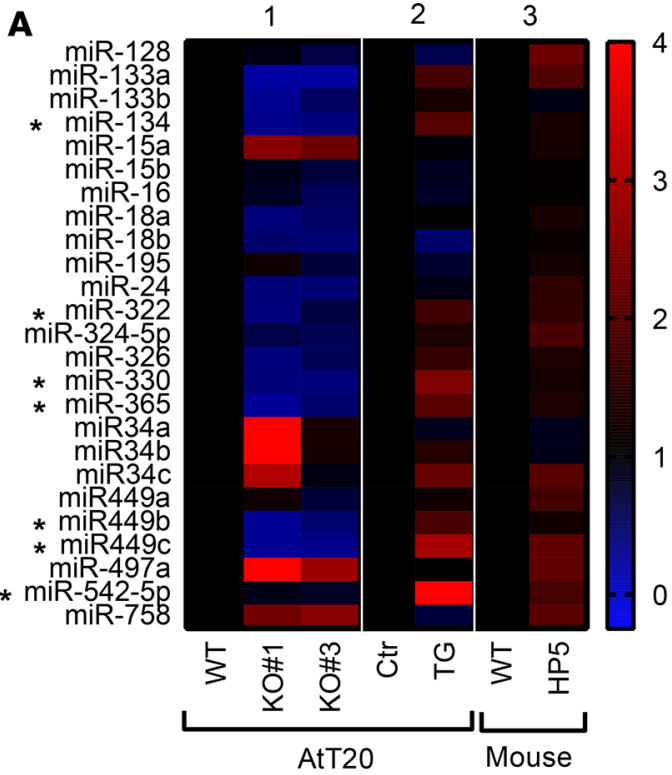

C

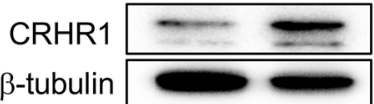

E

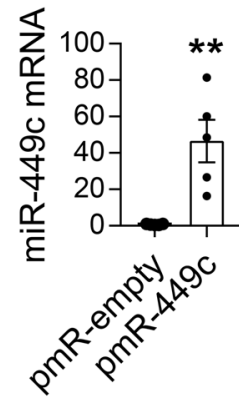

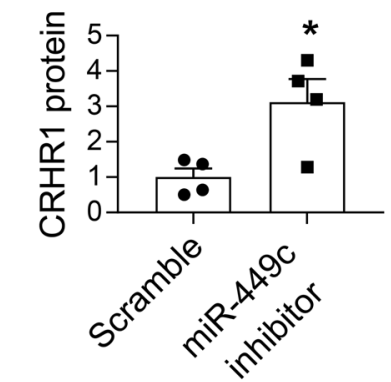

$\mathbf{F}$

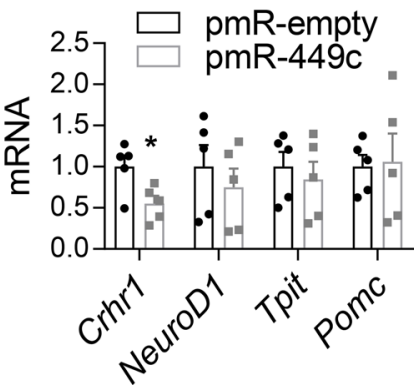

B
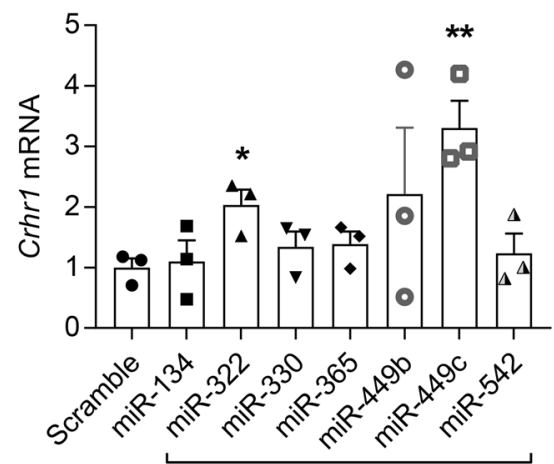

miRNA inhibitor oligonucleotides

D

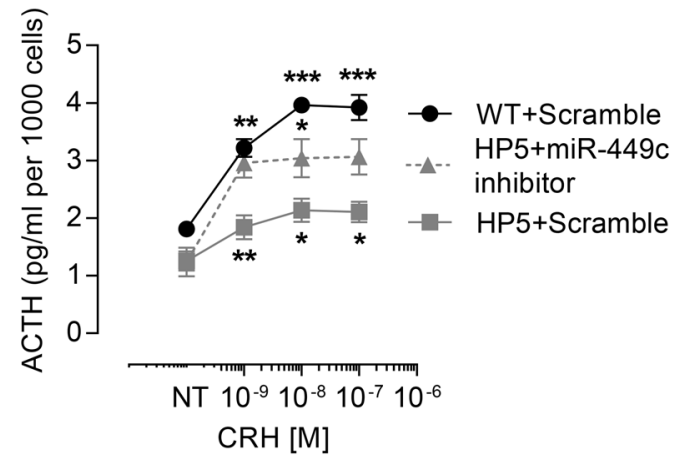

G

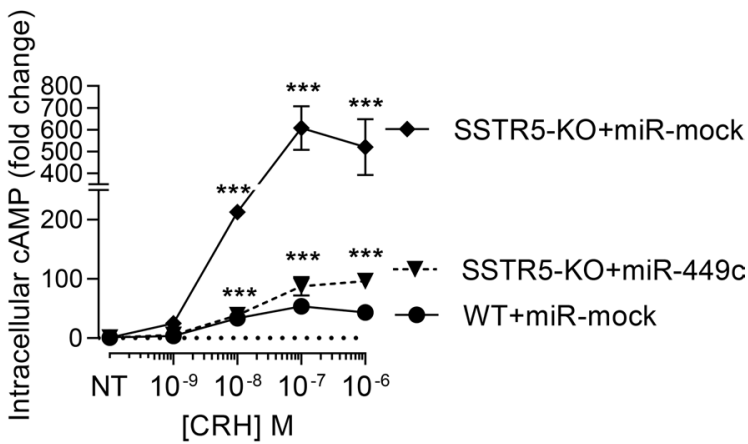

Figure 7. SSTR5 downregulates CRHR1 signaling via miRNA-449c. (A) Heatmap representing expression of candidate miRNAs that might bind Crhr1 3'UTR in (lane 1) SSTR5-KO AtT20 cells, (lane 2) SSTR5-overexpressing AtT20 cells, and (lane 3) HP5 and WT mouse pituitaries. Asterisks identify 7 candidate miRNAs that showed similar trends of change similar in lane 2 and lane 3 and an opposite trend in lane 1. Candidate miRNA expression levels were analyzed by qPCR, and levels of each miRNA were normalized to endogenous U6 small nuclear RNA. (B) Crhr1 mRNA level measured in WT AtT20 cells (2.0 $\times 10^{5}$ cells/well, $n=3$ ) 48 hours after transfection with $200 \mathrm{nM}$ miRNA inhibitors identified in $\mathbf{A}$ or scramble negative control. Chrh1 mRNA normalized to Gapdh and divided by the scramble control level. Experiments were repeated in quadruplicate, and representative results are shown. Nucleotide sequence of miRNA inhibitors is given in Supplemental Table 4. (C) Representative CRHR1 protein expression and quantitative densitometry analysis of receptor normalized to $\beta$-tubulin in WT AtT20 cells $(n=4)$ treated with miR-449c inhibitor. (D) CRH-stimulated ACTH levels measured by ELISA in the culture medium of whole pituitary glands $\left(8.0 \times 10^{4}\right.$ cells/well, $n=4$ at each CRH concentration) collected from WT $(n=4)$ and HP5 $(n=6)$ mice. ACTH level (pg/ml)

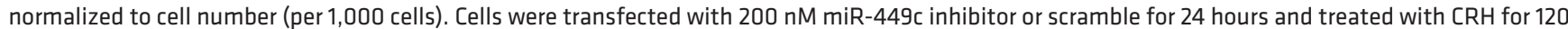
minutes, and culture medium was collected. $Y$ axis represents fold change in ACTH from respective CRH-untreated cells (NT). Each value represents the average of triplicate experiments. (E) miRNA-449c expression in AtT20 cells transfected with plasmid carrying miRNA-449c (pmR-449c) or empty plasmid (pmR-empty) normalized to endogenous U6 small nuclear RNA. Relative mRNA expression levels were normalized to Gapdh. Results represent the combination of 3 experiments performed in quadruplicate. (F) mRNA levels of indicated genes in AtT20 cells overexpressing miRNA-449c (pmR-449c) compared with cells expressing empty vector (pmR-empty). Results represent the combination of 3 experiments performed in quadruplicate. (G) SSTR5-K0\#3 AtT20 cells transfected with pmR-449c or pmR-empty compared with similarly transfected WT cells for 48 hours and treated with increasing doses of CRH for 30 minutes, after which intracellular cAMP was measured by LANCE cAMP assay $\left(8.0 \times 10^{4}\right.$ cells/well, $n=4$ for each CRH concentration). $Y$ axis represents fold change in cAMP from control CRH-untreated cells (NT). Experiments were performed in triplicate. Results are presented as mean $\pm \mathrm{SEM}$. ${ }^{*} P \leq 0.05$; ${ }^{* *} P \leq$ $0.01 ;{ }^{* *} P \leq 0.001 ;$ 2-tailed unpaired $t$ test, (D and $\left.\mathbf{G}\right)$ with Bonferroni correction. 
Moreover, HP5 mice exhibit increased anxiety-like behavior, as demonstrated by less center activity and rearing behavior. Anxious behavior, a recognized feature of secondary AI $(9,50)$, is known to result from altered CRH signaling. Mice treated with a CRHR1 antagonist, as well as CRHR1-KO mice, display decreased anxiety $(16,51)$, while $\mathrm{CRH}$-overexpressing $\mathrm{Tg}$ mice exhibit increased anxiety compared with CRH-KO mice $(51,52)$. The higher anxiety levels seen in HP5 mice likely results from a lack of negative feedback regulation on $\mathrm{CRH}$, driven by reduced pituitary ACTH and peripheral corticosterone. Depressive mood, another behavioral symptom exhibited by patients with secondary AI (50), is also manifested in HP5 mice, which stopped swimming earlier on the forced swim test compared with WT mice. HP5 mice also exhibited greater deterioration in their health status upon treatment with LPS. HP5 mice are therefore a model for mild secondary AI, which present as clinically "normal" at baseline but show anxiety- and depressive-like behaviors and deteriorated health status upon exposure to an inflammatory challenge. The HP5 mouse is likely more clinically useful than other mouse models for simulating features of mild human secondary AI.

Several studies, including those from our laboratory, show SSTR5 activation leading to suppressed CRH signaling (29-31). In AtT20 cells that express SSTR2, SSTR3, and SSTR5, the SSTR1/SSTR5 selective agonist L-817,818 inhibited CRH-induced ACTH secretion (53). Similarly, pasireotide inhibited CRH-dependent ACTH secretion in rat, murine, and human pituitary cultures $(30,31)$. Constitutive SSTR5 activity in AtT20 cells also markedly suppressed CRH-induced ERK phosphorylation, as well as induction of intracellular cAMP levels and ACTH secretion in AtT20 cells (29).

Somatostatin directly inhibits exocytosis via inhibition of cAMP accumulation and calcium fluxes, thereby inhibiting hormone secretion (54). We now extend this understanding of somatostatin function by showing that SSTR5 negatively regulates ACTH production via posttranscriptional microRNA regulation of CRHR1. miR-34a is known to bind the 3'UTR of CRHR1 and, when overexpressed in human lymphocytes, downregulates CRHR1 expression and CRH signaling (55). In addition, miR449a levels are increased in pituitary cells shortly after mice undergo a restraint test and/or are treated with dexamethasone, while overexpressed miR-449a suppresses CRHR1 (56). We found that, in mice overexpressing SSTR5, miR-449c specifically targets the CRHR1 3'UTR region. Consistent with these findings, HP5 mouse pituitaries and SSTR5-overexpressing AtT20 cells express higher levels of miR-449c and low CRHR1. The functional link between miR-449c and CRHR1 was further validated by showing that overexpressed miR-449c decreases CRHR1 expression, while miR-449c KO increases CRHR1 expression. Thus, we conclude that increased corticotroph SSTR5 and miR-449c expression act to downregulate CRHR1 posttranscriptional expression, reducing CRHR1 levels and corticotroph responses to CRH. Using this model, we elucidate a potentially novel mechanism by which SSTR5 controls $\mathrm{CRH}$ action and causes secondary AI.

It is possible that SSTR5 suppresses CRHR1 function by modifying the CRHR1 isoform expression profile, as several exhibit reduced activation of CRHR1 by CRH (57). Future studies will seek to define which CRHR1 isoform is involved in SSTR5 signaling through CRH.

A second potential limitation of our study is our reliance on $1 \mathrm{Tg}$ founder. To minimize the possibility that expression profiles and responses were founder specific, we initially generated 3 separate Tg mice. All 3 showed similar expression of HA-hSSTR 5 on IHC, and we selected 1 at random to serve as founder for further propagation.

In conclusion, we have developed a Tg mouse that demonstrates SSTR5 regulation of the HPA axis to generate biochemical and clinical features of secondary AI. We also show that, in addition to acute inhibition of pituitary ACTH secretion, SSTR5 posttranscriptionally suppresses CRHR1 via miR-449c, resulting in attenuated corticotroph responses to hypothalamic CRH. The HP5 mouse provides new insight into somatostatin receptor regulation of the HPA axis and recapitulates clinical and biochemical features of a mild form of secondary AI.

\section{Methods}

\section{Study design}

The objective of this study was to determine whether corticotroph SSTR5 attenuates the HPA axis stress response and to elucidate mechanisms by which it occurs. We evaluated the HPA axis stress response in a potentially novel corticotroph-specific SSTR5-overexpressing HP5 mouse model with different stress challenges, including biochemical stimulation $(\mathrm{CRH})$, behavioral stimulation (restraint, open field test, 
and forced swimming tests), and inflammatory challenge (LPS injection). To study mechanisms by which these occur, we assessed CRHR1 expression and response to SSTR5 levels in vivo, ex vivo, and in vitro (overexpression or KO of SSTR5 in AtT20 cells). As no effect on CRHR1 promoter activity was evident, we analyzed CRHR1-targeting miRNAs by qPCR, Western blotting, ELISA, cAMP assay, IHC, luciferase assay, and ChIP assay. Sample sizes for the animal studies were determined by the Biostatistics \& Bioinformatics Core at Cedars-Sinai Medical Center.

\section{Treatments}

$\mathrm{CRH}$ (MilliporeSigma) and AVP (Abcam) were resuspended in sterile $\mathrm{ddH}_{2} \mathrm{O}$. LPS from Escherichia coli O111:B4 (MilliporeSigma) was resuspended in PBS. Forskolin (MilliporeSigma) was resuspended in dimethylsulfoxide. Pasireotide and octreotide (Novartis Pharmaceuticals) were resuspended in sterile $\mathrm{ddH}_{2} \mathrm{O}$. BIM-23206 (Ipsen) was prepared in $0.01 \mathrm{M}$ acetic acid and 0.1\% BSA as described (58).

Generation of $\mathrm{Tg}$ (HP5) mice. hSSTR5 cDNA was inserted downstream of the Pomc-enhancer-neuroD1Tpit/Pitx1 (PENT) promoter in mouse pituitary corticotroph cells as described (36). cDNAs encoding hSSTR 5 were provided by Graeme Bell (University of Chicago, Chicago, Illinois, USA). Xho I (5' end) and EcoRV ( $3^{\prime}$ end) were introduced by PCR, and the hSSTR 5 fragment joined upstream of $\mathrm{HA} \times 3$ sequences. The PENT promoter fragment in pGL4 vector was digested with NheI and Xho I and was inserted into the HA $\times 3$ sequence containing hSSTR 5 cDNA vector. PENT-hSSTR 5 expression constructs were microinjected into male pronuclei of fertilized eggs, and injected eggs were transplanted to pseudopregnant foster mothers (FVB/NJ background; The Jackson Laboratory). Genomic DNA isolated from offspring 10-14 days old using a KAPA Mouse Genotyping Kit (KAPABIOSYSTEM) was analyzed by PCR using primers binding the POMC promoter (POMC-F: 5' - GGTCACGTCCAAGGCTCACCCA - 3') and SSTR5 cDNA (SSTR5-R: 5' - CGTCCTGTTGTCACCGCCTCCA - 3').

Backcross generations used in the present study ranged from F4-F9. Mice (females, 6-12 months old) were maintained in a pathogen-free temperature-controlled $\left(23^{\circ} \mathrm{C}\right)$ mouse facility on the light/dark cycle (lights were on from 6 a.m. to 8 p.m.). Food and water were given ad libitum. Mice were fed with a normal diet (PicoLab Rodent Diet 20, Lab Supply). No more than 5 mice were housed per cage.

Blood collection and hormone analyses. Blood samples were collected by retro-orbital bleeding under anesthesia. After baseline samples were collected between 8 and 9 a.m. after an overnight fast, female mice were returned to their cages for 2 hours under fasting. Mice were injected i.p. with $40 \mu \mathrm{g} / \mathrm{kg} \mathrm{CRH}$. At 30 minutes after injection, blood samples were collected under anesthesia to obtain peak hormonal values.

Restraint test. On the first day, baseline blood samples were collected, female mice were returned to cages, and feeding resumed on a regular diet. On the second day, mice were manually restrained and placed into flat-bottomed restrainers $(5 \times 11 \times 4 \mathrm{~cm}$; Braintree Scientific Inc.) for 30 minutes without anesthesia. Immediately after removal from restraints, mice were euthanized, and blood and tissue were collected.

LPS challenge test. After baseline blood samples were collected, female mice were returned to cages for 2 hours under fasting and were then injected i.p. with LPS $5 \mathrm{mg} / \mathrm{kg}$ or $10 \mathrm{mg} / \mathrm{kg}$. After 3 hours, retro-orbital blood was drawn from the opposite eye under anesthesia. Mice were then returned to cages, and feeding resumed. All mice were euthanized on day 3 after LPS administration, and blood and tissue were collected.

Pasireotide injection test. Experimental design is shown in Supplemental Figure 3A. Female mice were injected s.c. with pasireotide LAR $40 \mathrm{mg} / \mathrm{kg}$ under anesthesia at 9 a.m. every 2 weeks for a total of 3 injections (days $0,14,28$ ). The $\mathrm{CRH}$ stimulation test was performed 1 week after the last injection.

Open field test. Female mice were moved into the test room in the Cedars-Sinai Rodent Bio-Behavior Core to habituate the day prior to the test. As this test measures spontaneous motor behavior, it was conducted first to avoid lingering effects from prior handling and manipulations. The open field apparatus is a 16-inch square, clear Plexiglas chamber with 15-inch high walls and an open top, surrounded by 2 rings of photobeams and optical sensors. The morning after transfer to the test room, mice were individually placed into the chamber, and photobeam breaks automatically recorded and were used to measure horizontal locomotor and rearing activity. Parameters recorded included general motor activity (number of beam breaks), number of times rearing, speed, distance traveled, and total resting time $(59,60)$.

Forced swim test. Female mice were moved into the test room in the Cedars-Sinai Rodent Bio-Behavior Core to habituate the day before the forced swim test, which measures behaviors that are indicators of despair in rodents $(61,62)$. The next morning, mice were individually placed into a large fully transparent container (40 cm height, $20 \mathrm{~cm}$ diameter) filled with water sufficient for the rodent to be fully submerged yet 
not to escape from the sides. Water temperature was maintained at $22^{\circ} \mathrm{C}-24^{\circ} \mathrm{C}$, and mice were tested for 6 minutes. Mice were rated for immobility (defined as the absence of activity) and escape-oriented behaviors including swimming, climbing, and diving. Data were recorded and analyzed for 6 minutes.

Food consumption. Individual 3-month-old female mice were kept in metabolic cages (Nalgene Metabolic Cage - Single Mouse, Ancare Corp.) for 3 days for 24 hours to allow for acclimation and were then fed with Nutra-Gel Diet (Bio-Serv) to reduce the risk of sample contamination. Food consumption was measured by the difference in food weight before and after feeding for 2 days.

\section{Cell cultures}

AtT20. AtT20/D16v-F2 cells stably expressing hSSTR5-IRES-ZsGreen and AtT20/D16v-F2 cells expressing only pZsGreen1-N1 (29) were grown in serum-containing low-glucose DMEM (Invitrogen) supplemented with 10\% FBS (Omega Scientifics), with the addition of 1\% glutamine, 1\% penicillin/streptomycin (Invitrogen) and geneticin $400 \mu \mathrm{g} / \mathrm{ml}$ (Invitrogen), in $6 \% \mathrm{CO}_{2}$ in a $37^{\circ} \mathrm{C}$ humidified incubator (29).

Primary mouse pituitary cell cultures. Primary mouse pituitary cells were isolated using the Neural Tissue Dissociation Kit (Miltenyi Biotec Inc.), plated in 48-well plates precoated with ECL Cell Attachment Matrix (MilliporeSigma), and attached after overnight incubation. Cells were cultured in serum-containing high-glucose DMEM (Invitrogen) supplemented with 10\% FBS (Omega Scientifics), with the addition of $1 \%$ glutamine and $1 \%$ penicillin/streptomycin (Invitrogen), in $6 \% \mathrm{CO}_{2}$ in a $37^{\circ} \mathrm{C}$ humidified incubator. Cells were then stimulated for 2 hours with increasing doses of $\mathrm{CRH}$ in serum-free medium, after which culture medium was collected for analysis. ACTH concentrations were corrected for cell number in each well.

\section{KO of SSTR5 by CRISPR/Cas9}

CRISPR/Cas9 reagents pSpCas9(BB)-2A-GFP (pX458, Addgene, 48138) were obtained from the Zhang laboratory via Addgene. Online CRISPR design tools were provided by Zhang Laboratory (http://crispr. mit.edu/) and CHOPCHOP (https://chopchop.rc.fas.harvard.edu/). Guides were selected for the fewest potential off-target sites and, where possible, the fewest potential off-target sites within coding exons. Guide sequences (sequence-PAM) were as follows: SSTR5KO\#1 (exon 1, 40-bp deletion): A, GCACAGGCACTAATACCGCC-CGG and B, GTTGGTATGCACCGTGGGAC-TGG; SSTR5KO\#2 (exon 1, 37-bp deletion): A, CACAGGCACTAATACCGCCC-GGG and B, TACTTGTTGGTATGCACCGT-GGG; SSTR5KO\#3 (exon 1, 47-bp deletion): A, AATACCGCCCGGGCTCCCAT-GGG and B, TACTTGTTGGTATGCACCGT-GGG. Guide sequences (without PAM) were cloned into pX458 and cotransfected into AtT20 cells using Neon Transfection System (Invitrogen) using $1150 \mathrm{~V}$ for $30 \mathrm{~ms}$ in 2 pulses. After 48 hours, transfected cells were individually placed into single wells of a 96-well plate. Isolated cell clones were grown and tested using genotyping primers (forward, 5' - GCTTCCAGCAGTAGCCATAA - 3' and reverse, $5^{\prime}$ - CAGGAAAGGAAGCCCCAACA - 3') that spanned the deleted genomic region. Clones were also PCR amplified and sequenced to verify the out-of-frame deletion in genomic material. The SSTR5 mutant clones were confirmed with disruption of SSTR5 function on intracellular CAMP assay using forskolin and BIM-23260 (Supplemental Figure 4E).

\section{Transfections}

Transfections of plasmid or microRNA inhibitors to cells were performed by Neon Transfection System (Thermo Fisher Scientific) at room temperature using $1150 \mathrm{~V}$ for $30 \mathrm{~ms}$ in 2 pulses for AtT20 cells or $1700 \mathrm{~V}$ for $20 \mathrm{~ms}$ in 1 pulse for primary mouse pituitary cells, with $100 \mu \mathrm{R}$ buffer for $2.0 \times 10^{6}$ cells/each reaction.

\section{Immunoblotting}

Total cell lysate was prepared in RIPA buffer (MilliporeSigma) containing Protease Inhibitor Cocktail (MilliporeSigma). For Western blot analysis, proteins were separated by SDS/PAGE, electroblotted onto TransBlot Turbo Transfer Pack 0.2- $\mu \mathrm{m}$ PVDF membrane (Bio-Rad), and incubated with Blocking One (Nacalai USA Inc.) for 20 minutes; they were then incubated overnight with primary antibodies at $4^{\circ} \mathrm{C}$. The following day, membranes were incubated with corresponding secondary antibodies for 2 hours at room temperature. Both primary and secondary antibodies were resuspended into Signal Enhancer HIKARI (Nacalai USA). Protein concentration was measured by DC protein assay kits (Bio-Rad), and absorbance was measured at $750 \mathrm{nM}$ with the Victor ${ }^{3}$ spectrophotometer (Perkin Elmer). Loading quality was confirmed by Ponceau S (MilliporeSigma) staining. 


\section{Immunofluorescence}

Mouse pituitary glands were fixed in 10\% formalin and embedded in paraffin. After deparaffinization and antigen retrieval, slides were blocked in Blocking One Histo (Nacalai USA), incubated overnight with rabbit polyclonal anti-hSSTR5 antibodies (1:100, Abcam; catalogs ab109495 and ab138863, 1:100, Santa Cruz Biotechnology Inc.; catalog sc-25679) and mouse monoclonal anti-ACTH (1:500, Abcam; ab20358). After washing, samples were incubated with Alexa Fluor chicken anti-mouse $488(\mathrm{H}+\mathrm{L}, 1: 500$ dilution, Invitrogen; catalog A-21200) and Alexa Fluor chicken anti-mouse 647 (H+L, 1:500 dilution, Invitrogen; catalog A-21463) mounted with Prolong Gold antifade reagent (Invitrogen). Confocal microscope images were obtained using True Confocal Scanner (Leica Microsystems) in dual-emission mode to separate auto-fluorescence from specific staining.

\section{Antibodies}

Anti-CRHR1 antibody (1:1,000, Aviva Systems Biology; catalog OASG01837), anti-hSSTR5 (1:1,000, Abcam; catalog ab109495) (63, 64), HA-tag (1:1,000, Cell Signaling; catalog 3724), $\beta$-tubulin (1:1,000, Abcam; catalog ab6046), rat GH (1:3,000, R\&D Systems; catalog MAB1566), ACTH (1:2000, Abcam; catalog ab20358), PC1/3 (1:1,000, Cell Signaling Technologies; catalog 11914S), PC2 (1:1,000, Cell Signaling Technologies; catalog 14013), AVP (1:1,000, MilliporeSigma; catalog AB1565), HA (1:1,000, Cell Signaling Technologies; catalog 3724), and c-Myc (1:1,000, Cell Signaling Technologies; catalog 5605) were purchased. Tpit antibody $(1: 1,000)$ was provided by Jacques Drouin (Clinical Research Institute of Montreal, Montreal, Quebec, Canada).

\section{Assays}

Hormones were assessed using ACTH ELISA kit (MD Biosciences Inc.), Corticosterone Double Antibody RIA Kit (MP Biomedicals), $\alpha \mathrm{MSH}$ (Human, Rat, Mouse) EIA Kit (Phoenix Pharmaceuticals Inc.), Mouse/Rat IGF-I ELISA kit (ALPCO Ltd.), Prolactin Mouse ELISA kit (Thermo Fisher Scientific), Rat/ Mouse Insulin ELISA (LINCO Research), and One Touch Ultra for glucose (Johnson \& Johnson).

cAMP assay. Cells seeded overnight at a density of $8 \times 10^{4}$ cells/well in a 48 -well plate were stimulated for 30 minutes at $37^{\circ} \mathrm{C}$ in medium containing $0.3 \%$ BSA and $1 \mathrm{mM}$ 3-isobutyl-1-methylxanthine (MilliporeSigma) supplemented with indicated treatments. Duplicate samples were assayed for cAMP levels with the LANCE cAMP Kit (PerkinElmer) and modified for intracellular cAMP measurement. Results were extrapolated from standard curves measured by the Victor ${ }^{3}$ spectrophotometer (PerkinElmer) (65).

Luciferase assay. The mouse Crhr1 promoter $(-1,400$ to +68$)$ was PCR amplified from genomic DNA (AtT20 cells) and cloned. Promoter regions were amplified using 5' primers binding to $-1,334,-912,-728$, -466 , and -266 (containing Xho I site at the $5^{\prime}$ end) and 3' primer binding to -13 (containing Hind III sites at the $3^{\prime}$ end). Resulting amplified fragments were digested with Xho I and Hind III and cloned into Xho I and Hind III sites in pGL3 basic vector. DNA sequences of inserted fragments were determined to remove defective fragments generated by PCR errors. Luciferase reporter assays were performed in $8 \times 10^{4}$ AtT20 cells with $0.5 \mu \mathrm{g}$ luciferase reporter plasmids, and $10 \mathrm{ng}$ pRL-CMV was used as an internal control plasmid. Cells were transfected using lipofectamine 2000 (Invitrogen) and cultured in $1 \mathrm{ml}$ medium in 48-well plates. Forty-eight hours after transfection, cells were harvested, and luciferase activity was analyzed by Dual-Luciferase Reporter Assay System (Promega). Assays were repeated at least 3 times, and luciferase activity was normalized by internal renilla activity.

ChIP assay. Two million AtT20 cells were fixed for 10 minutes at room temperature in 1\% formaldehyde, $4.5 \mathrm{mM}$ HEPES (pH 8.0), $9 \mathrm{mM} \mathrm{NaCl}, 0.09 \mathrm{mM}$ EDTA, and $0.045 \mathrm{mM}$ EGTA and sonicated (Nanoruptor, NR-350, Cosmobio Co. Ltd.) in lysis buffer (1\% SDS, 10 mM EDTA, and $50 \mathrm{mM}$ Tris-HCl [pH 8.0]) with proteinase inhibitor (MilliporeSigma P8340). ChIP Assay Kit (MilliporeSigma) was used, and precleared lysates were incubated overnight at $4{ }^{\circ} \mathrm{C}$ with polyclonal anti-acetyl histone H4 (Millipore) or control rabbit IgG (Santa Cruz Biotechnology Inc.). DNA fragments were isolated from immunoprecipitated chromatin and analyzed by real-time PCR with SsoAdvance SYBR Supermix (Bio-Rad). ChIP PCR primers are shown in Supplemental Table 1.

\section{RNA extraction and real-time PCR}

RNA was collected with RNeasy Mini Kit (QIAGEN). cDNA was synthesized from $1 \mu \mathrm{g}$ purified RNA by the iScript Reverse Transcription Supermix for qPCR (Bio-Rad). qPCR was performed in $10 \mu 1$ reactions 
using SsoAdvanced Universal SYBR Green Supermix in CFX96 or 384 instrument (Bio-Rad). Nucleotide sequence of primers is given in Supplemental Table 2. TaqMan Gene Expression Assays (Applied Biosystems) were used to analyze hSSTR5 expression (Hs00990408_s1). TaqMan mouse GAPDH Expression Assays with probe tagged with VIC (Applied Biosystems) were used as reference genes.

\section{MicroRNA}

Analysis. Total RNA for miRNA expression analysis was extracted from cells using TRIzol reagent (Invitrogen). Mir-X miRNA First-Strand Synthesis Kit and Mir-X miRNA qRT-PCR SYBR Kit (Clontech; Takara Bio Inc.) were used to analyze miRNA expression. miRNA primer sequences were obtained from miRBase (http://www.mirbase.org/) (Supplemental Table 3). Ct values $>35$ were removed from analysis. Expression levels were normalized by U6 with primers provided in the Mir-X miRNA qPCR SYBR Kit (Clontech; Takara Bio Inc.).

Overexpression and inhibition of miRNA. mmu-miR-449c (NR_030452.1) was PCR amplified using a set of primers (forward, 5' - GCTAGATCTAGGATGAAGTGTGGGTGTG - 3', containing Bgl II site at the 5'-end, and reverse, 5' - CACGGATCCGCATGCTTCTGAGTG - 3', containing BamH I sites at the 3'-end) from genomic mouse DNA and cloned. Resulting amplified fragments were digested with and cloned into Bgl II and BamH I in pmR-ZsGreen1 miRNA overexpression vector (Clontech; Takara Bio Inc.). Steric blocking miRNA inhibitors that hybridize to mature miRNAs and NC5 negative control were purchased from Integrated DNA Technologies Inc. Primary mouse pituitary cells or AtT20 cells were transfected with our constructs by Neon Transfection System (Invitrogen) using $1150 \mathrm{~V}$ for $30 \mathrm{~ms}$ in 2 pulses for AtT20 cells and $1700 \mathrm{~V}$ for $20 \mathrm{~ms}$ in 1 pulse for primary mouse pituitary cells, both with $100 \mu \mathrm{R}$ buffer. Experiments were performed after 48 hours.

\section{Statistics}

Statistical analyses were performed with GraphPad Prism 7.0 (GraphPad Software Inc.). Comparisons were analyzed by unpaired 2-tailed Student's $t$ test. Multiple-comparisons were analyzed by unpaired 2 -tailed Student's $t$ test with the Bonferroni correction. $P \leq 0.05$ was considered statistically significant.

\section{Study approval}

Animal care and handling was approved by the Cedars-Sinai IACUC (protocol no. 3392) and in accordance with the Guide for the Care and Use of Laboratory Animals (National Academies Press, 2011).

\section{Author contributions}

ABS and SM designed the study, and MY and HK performed the experiments. MY, ABS, HK, ND, and SM analyzed the data, and MY, ABS, and SM wrote the manuscript. HF created and provided plasmid used to express SSTR5 in corticotroph cells, and ABS generated the Tg mice. ED assisted with sample collection and provided technical assistance.

\section{Acknowledgments}

This work was supported by NIH grants DK113998 and DK007770 and the Doris Factor Molecular Endocrinology Laboratory at Cedars-Sinai. The authors thank Lihua Xia for assistance in conducting mouse experiments; Jean-Philippe Vit and the Cedars-Sinai Preclinical Biobehavioral Research Core for conducting mouse behavior studies; Kolja Wawrowsky and the Cedars-Sinai Confocal and Two-Photon Fluorescence Microscopy Core for conducting confocal imaging studies; Makoto Katsumata and the Cedars-Sinai Rodent Genetics Core for their assistance in generating Tg mice; and Shira Berman for assistance with manuscript preparation.

Address correspondence to: Shlomo Melmed, Cedars Sinai Medical Center, 8700 Beverly Boulevard, Room 2015, Los Angeles, California 90048, USA. Phone: 310.423.4691; Email: melmed@csmc.edu.

1. Chrousos GP. The hypothalamic-pituitary-adrenal axis and immune-mediated inflammation. N Engl J Med. 1995;332(20):1351-1362.

2. Turnbull AV, Rivier CL. Regulation of the hypothalamic-pituitary-adrenal axis by cytokines: actions and mechanisms of action. Physiol Rev. 1999;79(1):1-71.

3. Chrousos GP. Stressors, stress, and neuroendocrine integration of the adaptive response. The 1997 Hans Selye Memorial Lec- 
ture. Ann N Y Acad Sci. 1998;851:311-335.

4. Miller WL, Auchus RJ. The molecular biology, biochemistry, and physiology of human steroidogenesis and its disorders. Endocr Rev. 2011;32(1):81-151.

5. Crowley RK, Argese N, Tomlinson JW, Stewart PM. Central hypoadrenalism. J Clin Endocrinol Metab. 2014;99(11):4027-4036.

6. Hannon MJ, O'Halloran DJ. Isolated acquired ACTH deficiency and primary hypothyroidism: a short series and review. Pituitary. 2011;14(4):358-361.

7. Nowakowski KJ, Tucci JR. Idiopathic isolated ACTH deficiency and the response to CRF. J Endocrinol Invest. 1989;12(4):253-255.

8. Andrioli M, Pecori Giraldi F, Cavagnini F. Isolated corticotrophin deficiency. Pituitary. 2006;9(4):289-295.

9. Tiemensma J, et al. Psychological morbidity and impaired quality of life in patients with stable treatment for primary adrenal insufficiency: cross-sectional study and review of the literature. Eur J Endocrinol. 2014;171(2):171-182.

10. Charmandari E, Nicolaides NC, Chrousos GP. Adrenal insufficiency. Lancet. 2014;383(9935):2152-2167.

11. Else T, Hammer GD. Genetic analysis of adrenal absence: agenesis and aplasia. Trends Endocrinol Metab. 2005;16(10):458-468

12. Lamolet B, et al. A pituitary cell-restricted $\mathrm{T}$ box factor, Tpit, activates POMC transcription in cooperation with Pitx homeoproteins. Cell. 2001;104(6):849-859.

13. Pulichino AM, et al. Human and mouse TPIT gene mutations cause early onset pituitary ACTH deficiency. Genes Dev. 2003;17(6):711-716

14. Muglia LJ, et al. Corticotropin-releasing hormone links pituitary adrenocorticotropin gene expression and release during adrenal insufficiency. J Clin Invest. 2000;105(9):1269-1277.

15. Muglia LJ, Jacobson L, Weninger SC, Karalis KP, Jeong K, Majzoub JA. The physiology of corticotropin-releasing hormone deficiency in mice. Peptides. 2001;22(5):725-731.

16. Smith GW, et al. Corticotropin releasing factor receptor 1-deficient mice display decreased anxiety, impaired stress response, and aberrant neuroendocrine development. Neuron. 1998;20(6):1093-1102.

17. Karalis K, Mastorakos G, Sano H, Wilder RL, Chrousos GP. Somatostatin may participate in the antiinflammatory actions of glucocorticoids. Endocrinology. 1995;136(9):4133-4138.

18. Karalis K, Mastorakos G, Chrousos GP, Tolis G. Somatostatin analogues suppress the inflammatory reaction in vivo. J Clin Invest. 1994;93(5):2000-2006.

19. Brown MR, Rivier C, Vale W. Central nervous system regulation of adrenocorticotropin secretion: role of somatostatins. Endocrinology. 1984;114(5):1546-1549.

20. Kraicer J, Gajewski TC, Moor BC. Release of pro-opiomelanocortin-derived peptides from the pars intermedia and pars distalis of the rat pituitary: effect of corticotrophin-releasing factor and somatostatin. Neuroendocrinology. 1985;41(5):363-373.

21. Day R, Dong W, Panetta R, Kraicer J, Greenwood MT, Patel YC. Expression of mRNA for somatostatin receptor (sstr) types 2 and 5 in individual rat pituitary cells. A double labeling in situ hybridization analysis. Endocrinology. 1995;136(11):5232-5235.

22. Mezey E, et al. Cell specific expression of the sst2A and sst5 somatostatin receptors in the rat anterior pituitary. Endocrinology. 1998;139(1):414-419.

23. Viollet C, et al. Involvement of sst 2 somatostatin receptor in locomotor, exploratory activity and emotional reactivity in mice. Eur J Neurosci. 2000;12(10):3761-3770

24. White RE, Schonbrunn A, Armstrong DL. Somatostatin stimulates Ca(2+)-activated $\mathrm{K}+$ channels through protein dephosphorylation. Nature. 1991;351(6327):570-573.

25. Draznin B, Dahl R, Sherman N, Sussman KE, Staehelin LA. Exocytosis in normal anterior pituitary cells. Quantitative correlation between growth hormone release and the morphological features of exocytosis. J Clin Invest. 1988;81(4):1042-1050.

26. Tsaneva-Atanasova K, Sherman A, van Goor F, Stojilkovic SS. Mechanism of spontaneous and receptor-controlled electrical activity in pituitary somatotrophs: experiments and theory. J Neurophysiol. 2007;98(1):131-144.

27. Colao A, et al. A 12-month phase 3 study of pasireotide in Cushing's disease. N Engl J Med. 2012;366(10):914-924.

28. Ben-Shlomo A, Melmed S. Pituitary somatostatin receptor signaling. Trends Endocrinol Metab. 2010;21(3):123-133.

29. Ben-Shlomo A, et al. Constitutive somatostatin receptor activity determines tonic pituitary cell response. Mol Endocrinol. 2009;23(3):337-348.

30. Hofland LJ, et al. The multi-ligand somatostatin analogue SOM230 inhibits ACTH secretion by cultured human corticotroph adenomas via somatostatin receptor type 5. Eur J Endocrinol. 2005;152(4):645-654.

31. Silva AP, Schoeffter P, Weckbecker G, Bruns C, Schmid HA. Regulation of CRH-induced secretion of ACTH and corticosterone by SOM230 in rats. Eur J Endocrinol. 2005;153(3):R7-R10.

32. Strowski MZ, et al. Somatostatin receptor subtype 5 regulates insulin secretion and glucose homeostasis. Mol Endocrinol. 2003;17(1):93-106.

33. O'Carroll AM, Raynor K, Lolait SJ, Reisine T. Characterization of cloned human somatostatin receptor SSTR5. Mol Pharmacol. 1994;46(2):291-298

34. Lublin AL, Diehl NL, Hochgeschwender U. Isolation and characterization of the gene encoding the type 5 mouse (Mus musculus) somatostatin receptor (msst5). Gene. 1997;195(1):63-66.

35. Theodoropoulou M, Stalla GK. Somatostatin receptors: from signaling to clinical practice. Front Neuroendocrinol. 2013;34(3):228-252.

36. Araki T, et al. EGFR Induces E2F1-Mediated Corticotroph Tumorigenesis. J Endocr Soc. 2017;1(2):127-143.

37. Hammer GD, Fairchild-Huntress V, Low MJ. Pituitary-specific and hormonally regulated gene expression directed by the rat proopiomelanocortin promoter in transgenic mice. Mol Endocrinol. 1990;4(11):1689-1697.

38. Tremblay Y, Tretjakoff I, Peterson A, Antakly T, Zhang CX, Drouin J. Pituitary-specific expression and glucocorticoid regulation of a proopiomelanocortin fusion gene in transgenic mice. Proc Natl Acad Sci USA. 1988;85(23):8890-8894.

39. Langlais D, Couture C, Sylvain-Drolet G, Drouin J. A pituitary-specific enhancer of the POMC gene with preferential activity in corticotrope cells. Mol Endocrinol. 2011;25(2):348-359.

40. Trainor BC, et al. Sex differences in social interaction behavior following social defeat stress in the monogamous California mouse (Peromyscus californicus). PLoS ONE. 2011;6(2):e17405.

41. Grad B, Khalid R. Circulating corticosterone levels of young and old, male and female C57B1/6J mice. J Gerontol. 
1968;23(4):522-528

42. Hardiman A, et al. Endocrinomic profile of neurointermediate lobe pituitary prohormone processing in PC1/3- and PC2-Null mice using SELDI-TOF mass spectrometry. J Mol Endocrinol. 2005;34(3):739-751.

43. Stewart PM, Newwell-Price JDC. In: Melmed S, Polonsky KS, Larsen PR, Kronenberg HM, ed. Williams Textbook of Endocrinology. Philadelphia, PA: Elsevier; 2016:490-555.

44. Kehne JH, Cain CK. Therapeutic utility of non-peptidic CRF1 receptor antagonists in anxiety, depression, and stress-related disorders: evidence from animal models. Pharmacol Ther. 2010;128(3):460-487.

45. Parham KL, Zervou S, Karteris E, Catalano RD, Old RW, Hillhouse EW. Promoter analysis of human corticotropin-releasing factor (CRF) type 1 receptor and regulation by CRF and urocortin. Endocrinology. 2004;145(8):3971-3983.

46. Miao LJ, et al. MiR-449c targets c-Myc and inhibits NSCLC cell progression. FEBS Lett. 2013;587(9):1359-1365.

47. Preil J, et al. Regulation of the hypothalamic-pituitary-adrenocortical system in mice deficient for CRH receptors 1 and 2. Endocrinology. 2001;142(11):4946-4955.

48. Müller MB, et al. Selective activation of the hypothalamic vasopressinergic system in mice deficient for the corticotropin-releasing hormone receptor 1 is dependent on glucocorticoids. Endocrinology. 2000;141(11):4262-4269.

49. Müller MB, et al. Expression of CRHR1 and CRHR2 in mouse pituitary and adrenal gland: implications for HPA system regulation. Endocrinology. 2001;142(9):4150-4153.

50. Hahner S, et al. Impaired subjective health status in 256 patients with adrenal insufficiency on standard therapy based on cross-sectional analysis. J Clin Endocrinol Metab. 2007;92(10):3912-3922.

51. Weninger SC, et al. Stress-induced behaviors require the corticotropin-releasing hormone (CRH) receptor, but not CRH. Proc Natl Acad Sci USA. 1999;96(14):8283-8288.

52. Stenzel-Poore MP, Heinrichs SC, Rivest S, Koob GF, Vale WW. Overproduction of corticotropin-releasing factor in transgenic mice: a genetic model of anxiogenic behavior. J Neurosci. 1994;14(5 Pt 1):2579-2584.

53. Strowski MZ, et al. Somatostatin receptor subtypes 2 and 5 inhibit corticotropin-releasing hormone-stimulated adrenocorticotropin secretion from AtT-20 cells. Neuroendocrinology. 2002;75(6):339-346.

54. Andolina D, et al. Effects of lack of microRNA-34 on the neural circuitry underlying the stress response and anxiety. Neuropharmacology. 2016;107:305-316.

55. Shenoda BB, Alexander GM, Ajit SK. Hsa-miR-34a mediated repression of corticotrophin releasing hormone receptor 1 regulates pro-opiomelanocortin expression in patients with complex regional pain syndrome. J Transl Med. 2016;14:64.

56. Nemoto T, Mano A, Shibasaki T. miR-449a contributes to glucocorticoid-induced CRF-R1 downregulation in the pituitary during stress. Mol Endocrinol. 2013;27(10):1593-1602.

57. Slominski AT, Zmijewski MA, Zbytek B, Tobin DJ, Theoharides TC, Rivier J. Key role of CRF in the skin stress response system. Endocr Rev. 2013;34(6):827-884

58. Ben-Shlomo A, et al. Somatostatin receptor type 5 modulates somatostatin receptor type 2 regulation of adrenocorticotropin secretion. J Biol Chem. 2005;280(25):24011-24021.

59. Seibenhener ML, Wooten MC. Use of the Open Field Maze to measure locomotor anxiety-like behavior in mice. $J$ Vis Exp. 2015;(96):52434.

60. Borta A, Schwarting RK. Inhibitory avoidance, pain reactivity, and plus-maze behavior in Wistar rats with high versus low rearing activity. Physiol Behav. 2005;84(3):387-396.

61. Can A, Dao DT, Arad M, Terrillion CE, Piantadosi SC, Gould TD. The mouse forced swim test. J Vis Exp. 2012;(59):3638.

62. Kara NZ, Stukalin Y, Einat H. Revisiting the validity of the mouse forced swim test: Systematic review and meta-analysis of the effects of prototypic antidepressants. Neurosci Biobehav Rev. 2018;84:1-11.

63. Kaemmerer D, et al. Correlation of monoclonal and polyclonal somatostatin receptor 5 antibodies in pancreatic neuroendocrine tumors. Int J Clin Exp Pathol. 2013;6(1):49-54.

64. Lupp A, Hunder A, Petrich A, Nagel F, Doll C, Schulz S. Reassessment of sst(5) somatostatin receptor expression in normal and neoplastic human tissues using the novel rabbit monoclonal antibody UMB-4. Neuroendocrinology. 2011;94(3):255-264.

65. Eigler T, Ben-Shlomo A, Zhou C, Khalafi R, Ren SG, Melmed S. Constitutive somatostatin receptor subtype-3 signaling suppresses growth hormone synthesis. Mol Endocrinol. 2014;28(4):554-564. 